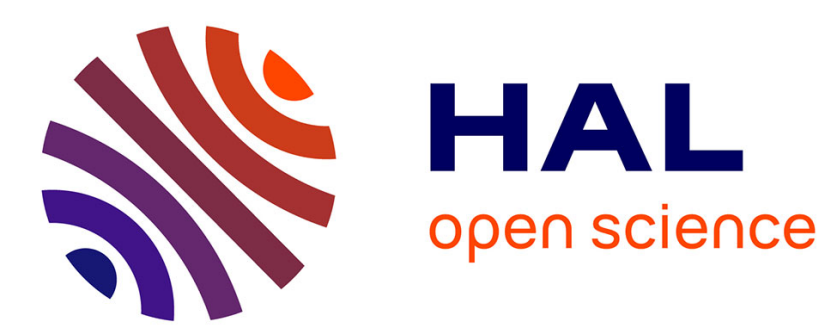

\title{
The Perception of Self in Birds
}

Sébastien Derégnaucourt, Dalila Bovet

\section{To cite this version:}

Sébastien Derégnaucourt, Dalila Bovet. The Perception of Self in Birds. Neuroscience and Biobehavioral Reviews, 2016, 69, pp.1-14. 10.1016/j.neubiorev.2016.06.039 . hal-01478442

\section{HAL Id: hal-01478442 \\ https://hal.parisnanterre.fr/hal-01478442}

Submitted on 21 Nov 2017

HAL is a multi-disciplinary open access archive for the deposit and dissemination of scientific research documents, whether they are published or not. The documents may come from teaching and research institutions in France or abroad, or from public or private research centers.
L'archive ouverte pluridisciplinaire HAL, est destinée au dépôt et à la diffusion de documents scientifiques de niveau recherche, publiés ou non, émanant des établissements d'enseignement et de recherche français ou étrangers, des laboratoires publics ou privés. 
4

$5 \quad{ }^{1}$ Laboratoire Ethologie Cognition Développement, LECD EA3456, Université Paris Ouest

6 Nanterre La Défense, 200 avenue de la République, F92001 Nanterre cedex, France

$7 \quad{ }^{2}$ Institut Universitaire de France

$8 *$ corresponding author

9 


\section{Abstract:}

11 The perception of self is an important topic in several disciplines such as ethology,

12 behavioral ecology, psychology, developmental and cognitive neuroscience. Self-

13 perception is investigated by experimentally exposing different species of animals to self-

14 stimuli such as their own image, smell or vocalizations. Here we review more than one

15 hundred studies using these methods in birds, a taxonomic group that exhibits a rich

16 diversity regarding ecology and behavior. Exposure to self-image is the main method for

17 studying self-recognition, while exposing birds to their own smell is generally used for the

18 investigation of homing or odor-based kin discrimination. Self-produced vocalizations -

19 especially in oscine songbirds - are used as stimuli for understanding the mechanisms of

20 vocal coding/decoding both at the neural and at the behavioral levels. With this review, we

21 highlight the necessity to study the perception of self in animals cross-modally and to

22 consider the role of experience and development, aspects that can be easily monitored in

23 captive populations of birds.

24 


\section{1. Introduction}

\section{1.1. The Concept of Self: definitions}

29 There is a biological necessity for distinguishing self from non-self at various levels of 30 organization: from physiological processes at the cellular level (e.g. to produce an immune 31 response) to individual-level behaviors, such as discriminating kin and identifying 32 conspecific and hetero-specific cues (Sherman et al., 1997). Lewis (1994) proposed a 33 distinction between two levels of self that are often confused: "the machine self", the 34 greater part of the self, which knows without knowing that it knows, and the "idea of me", 35 the smaller part - included in the machine self - which knows that it knows. The second 36 level refers to self-awareness, and involves the idea of consciousness which constitutes the 37 corner stone of the Theory of Mind (Edelman \& Seth, 2009).

38 To better understand the concept of the "machine self", we can refer to self-referent 39 phenotype matching. During its development, an animal learns some aspects of its own 40 phenotype, in particular through self-directed behaviors, which it later uses as a referent or 41 template to identify relatives (kin recognition) or conspecifics (species recognition) 42 (Hauber \& Sherman, 2001). Dawkins (1982) euphemistically called it the 'armpit' effect.

43 As underlined by Bekoff \& Sherman (2004) such self-referencing can be reflexive and 44 non-cognitive. These authors suggest two other degrees of self-cognizance: (1) self45 awareness, that enables an individual to discriminate consciously or subconsciously 46 between its own body or possessions from those of others, and (2) self-consciousness, 47 which involves having a sense of one's own body as a named self, and thinking about one's 
48 self and one's own behavior in relation to the actions of others. According to Bekoff \& 49 Sherman (2014), self-awareness does not imply that individuals use self-referent

50 phenotype matching or vice versa, whereas self-consciousness implies that an individual is 51 self-aware, and that it can use self-referencing. Therefore, self-referent phenotype 52 matching is probably a prerequisite for self-consciousness. However, other researchers do 53 not make the same distinction between self-awareness and self-consciousness and these 54 two expressions are often used with the same significance. For example, Lewis (2011) 55 defines self-awareness as "a mental representation of me."

\section{1.2. Mirror Self-Recognition}

59 Several experimental paradigms have been designed to explore these aspects of self-

60 awareness and self-consciousness in animals. Among them, the mirror mark test, 61 developed by Gordon Gallup (1970), seeks to determine whether an animal recognizes 62 itself in the mirror by marking a colored dot on the animal's body. The mark needs to be 63 placed on an out-of-view body part so that it can be detected only with guidance of a mirror. 64 This is done without the subject noticing (subjects were often anesthetized for the first 65 studies) or with a procedure of sham marking used as a control. The mark test determines 66 if the animal can use its reflection to locate the mark on its body, as measured by its 67 inspection, touching, or rubbing of the spot. Very few species pass the mark test of mirror 68 self-recognition (MSR) (Table 1).

69 In humans, MSR does not emerge until 15-24 months of age (Amsterdam, 1972; Lewis, 70 2011) when the first signs of self-awareness appear: these include introspection and mental 
71 state attribution (Piaget, 1952) along with empathy (Bischof-Kohler, 2012), the use of

72 personal pronouns and pretend play (Lewis \& Ramsay, 2004). Apart from humans, strong

73 evidence of MSR have been obtained only for the four great apes (Anderson \& Gallup,

74 2011), bottlenose dolphins (Tursiops truncatus; Reiss \& Marino, 2001), Asian elephants

75 (Elephas maximus; Plotnik et al., 2006) and magpies (Pica pica; Prior et al., 2008). A

76 variety of organisms including fishes, birds, sea lions, dogs and cats, although they have

77 not been formerly tested with the mirror mark test, produce very different behaviors toward

78 their own reflections (Parker et al., 1994). Several species persist in responding to mirrors

79 as if confronted by another conspecific, even in the case of years of continuous exposure

80 to mirrors (Suarez \& Gallup, 1986). Mirrors induce socially meaningful and strong

81 responses with such reliability that mirror-image stimulation has been extensively

82 employed to study aggressive and social patterns in a wide variety of species from fishes

83 to mammals (Parker et al., 1994). Some of these species demonstrate the ability to use a

84 mirror to mediate or guide their behavior, for example macaques (Macaca fuscata) can use

85 a mirror to reach hidden food that is only visible with a mirror (Itakura, 1987). However,

86 the conclusion that self-directed behavior in response to a mirror implies some form of

87 human-like self-awareness is not free from controversy (Parker et al., 1994). Similarly,

88 implication of self-recognition when passing the mark test is also a subject of debate

89 (Medina et al., 2011; Suddendorf \& Butler, 2013).

90 While visual self-stimuli have extensively been used in primates, there is debate as to the

91 value of tests that rely primarily on senses other than vision. The mirror test has been

92 adapted to other modalities, such as scent. For instance, Bekoff (2001) developed a

93 paradigm using urine-saturated snow ('yellow snow') for testing self-awareness in dogs. 
94 Besides their own reflection and their own smell, animals have also been exposed to their

95 own vocalizations, not necessarily in the context of studying self-awareness. Indeed, if self-

96 recognition is an important topic in comparative psychology or cognitive neuroscience,

97 exposure to self-stimuli is often used as a control in ethology or behavioral ecology. This

98 paradigm has been extensively used in bird species in different contexts, which we

99 summarize in the next section.

100

$101 \quad$ 1.3. Why study the perception of self in birds?

102

103 The class Aves is composed of about 10,000 species with a rich diversity regarding their 104 ecology and behavior.

105 Several experiments and observations in birds have indirectly shown that the perception of 106 self is particularly relevant during interactions with other individuals, especially in the 107 context of sexual selection. Monogamy is particularly widespread in birds and several 108 species exhibit assortative pairing: pairing with an individual of similar quality or 109 geographical origin. For example, non-random mating with respect to coloration is 110 commonly observed in birds (Hill, 2006). In domesticated budgerigars (Melopsittacus

111 undulatus), females prefer potential mates with contact calls more similar to their own

112 (Moravec et al., 2010). In the laboratory, Holveck and Riebel (2009) observed that female

113 zebra finches (Taeniopygia guttata) reared in poor conditions develop acoustic preferences

114 for the songs of males reared in similar conditions. Several experiments have also shown

115 that females reduce their choosiness when their body condition is experimentally

116 compromised (Burley \& Foster, 2006; Lerch et al., 2011, 2013). For example, cutting the 
117 flight feathers of female canaries (Serinus canaria) decreases female choosiness towards

118 male songs. The authors propose that this decrease in choosiness is likely to be a residual

119 behavioral adaptation of being in poor conditions and it follows the evaluation of their own

120 flight quality in the aviary and therefore results from the perception of self-properties

121 (Lerch et al., 2013).

122 The perception of self can also be affected by the experience of the animals. Some species

123 have the possibility to modify their self-characteristics through learning, and this is

124 particularly well-documented in some bird species in the vocal domain (Bolhuis et al., 125 2010; Bradbury \& Balsby, 2016). Like humans, oscine songbirds, parrots and 126 hummingbirds exhibit vocal production learning, the capacity to imitate sounds from their 127 environment, mainly those produced by conspecifics. This ability which is a prerequisite 128 for the development of human speech, is a rare trait in the animal kingdom and is shared 129 with certain marine mammals, elephants and bats but seems to be absent in non-human 130 primates (Bolhuis et al., 2010), although some vocal plasticity and abilities for vocal social 131 learning have recently been demonstrated in monkeys (Lemasson et al, 2005; Takahashi et 132 al., 2015). The architecture and connectivity of avian and mammalian brains are much 133 more similar than had been recognized previously (Reiner et al., 2004). For instance, avian 134 pallial 'song' regions bear functional similarities with human auditory and motor cortices 135 and the importance of the basal ganglia for both speech and birdsong is starting to be 136 understood mechanistically (Doupe et al., 2005; Jarvis et al., 2005; Mooney, 2009). These 137 aspects and others consolidate birdsong as the biological model of choice to study the 138 behavioral, molecular and cellular substrates of vocal learning, an important component of 139 language acquisition (Bolhuis et al., 2010). Studies that cannot be conducted on humans 
140 for obvious ethical reasons can easily be done with captive populations of oscine songbirds,

141 and exposing a bird to its own song is a useful method to investigate the neural substrates

142 for individual recognition. Here, we are not reviewing the literature dealing with exposure

143 to self-produced vocalizations in mammals, but it is likely that the number of studies would

144 be greatly outnumbered by those conducted in birds.

145 Besides the aspects linked to vocal learning, recent studies have shown that birds and 146 mammals faced a similar selection pressure for complex cognitive abilities, resulting in the

147 evolution of a comparable neural architecture of forebrain association areas as well as in 148 cognitive operations (Butler et al., 2005). The dorsal ventricular ridge (DVR) of the avian 149 brain contains neuronal populations homologous to those present in different layers of the 150 mammalian neocortex. The neurons of the avian DVR and mammalian cortex are nearly 151 identical in both their morphology and constituent physiological properties. Structural 152 homologies were also identified using molecular and immunohistological techniques. In 153 particular, neurotransmitters, neuropeptides, and receptors specific to particular neuronal 154 populations within mammalian brain regions have been localized to homologous avian 155 brain regions (Edelman \& Seth, 2009, Figure 1).

156 This high degree of evolutionary convergence is especially apparent in the cognitive 157 abilities of corvids and parrots, big-brained birds whose forebrains have a relative size the 158 same as those of apes, and who behaviorally perform at a comparable level with apes in 159 many domains such as episodic memory, tool-use and theory of mind (Figure 2; Emery \& 160 Clayton, 2004; Emery, 2006; Güntürkün \& Bugnyar, 2016; Van Horik \& Emery, 2011). In 161 the field of animal cognition, variants of the mirror test have been used in birds but so far 
162 only magpies have been shown to recognize their own reflection (Prior et al., 2008). We

163 will discuss this result later.

164 In the case of mirror self-recognition, the issue of self-perception is addressed directly. As

165 we presented before, the perception of self is an important issue in the social life of a bird

166 during encounters with other individuals such as during mate choice.

167 The aim of this article is to give a state of the art review of the different studies dealing

168 either directly or indirectly with the perception of self in birds across disciplines such as

169 developmental and cognitive neuroscience, animal psychology, ethology and behavioral

170 ecology. Birds have been exposed to self-stimuli through different sensory modalities:

171 vision, olfaction and audition.

172 For a long time, it was believed that birds had a poor sense of smell. But as we will

173 summarize, recent studies have shown that olfactory signals play an important role in

174 orientation and the social life of several bird species (Caro et al., 2015).

175 Finally, playback of birds' own vocalizations have been extensively used both in the field

176 and in the laboratory and in many species of birds. Oscine songbirds exhibit an especially

177 strong response to the broadcast of their own song, both at the behavioral and at the neural

178 levels. Such experiments have helped us decipher the mechanisms of vocal

179 coding/decoding for example during socio-sexual interactions such as territory defense.

180 Exposing a bird to its own vocal signature is a useful means to investigate the neural

181 substrates of individual recognition; a fruitful topic of research that has been barely

182 addressed in other sensory modalities. This topic has been also barely addressed in 183 mammals. 
184 Vocal learning allows fine vocal adjustments in some bird species and the perception of 185 self can also be addressed by an analysis of vocal labeling, namely the use of calls to 186 address a specific individual. Such vocal labeling has been shown in some parrot species

187 and people rearing parrots and corvids usually give names to their pets/experimental 188 subjects.

189 In this review, we want to stress the importance of experience and the social environment

190 during development in self-recognition; these aspects can easily be monitored in captive 191 populations of birds. In the concluding part of this review, we will propose future directions 192 to study the perception of self in birds including the multimodality of the perception of self 193 (use of different sensory modalities) and other aspects linked to emotions that could echo 194 recent realization in animal welfare.

196 2. Visual representations

198 2.1. Self-referent visual phenotype matching

200 Most birds learn conspecific characteristics from their parents and siblings. They probably 201 also take into account their own phenotype, and later match features of encountered 202 individuals to that template through self-referent phenotype matching. Such self203 referencing was studied with cross-fostered and naïve (raised in social isolation) chicks 204 (Gallus domesticus, Salzen \& Cornell, 1968; Vidal, 1975). Salzen and Cornell (1968) 205 conducted a series of experiments to test the hypothesis that self-perception explains 206 preferential choices of conspecifics by birds raised in isolation. They painted chicks with 
207 different colors and kept them in social isolation for 8 days before testing them in a 2-

208 choice experiment with a companion from the same color and another one with a different

209 color. The authors conclude that the self-perception hypothesis is tenable at least if

210 perception through reflection in water is included. Indeed, chicks reared in isolation with

211 no drinking trough (water was administered by pipette directly in the crop) failed to show

212 any tendency to choose a companion with their own color (Salzen \& Cornell, 1968). Even

213 with modifications to prevent self-reflection in water such as painting the bottom of

214 drinking trough in white (Vidal, 1975), there is evidence that birds can perceive their

215 shadow. For example, domestic roosters exhibit courtship displays towards their shadow

216 (Vidal, 1975). Vidal (1975) observed that an isolated cock perceived and fixated on parts

217 of its own body (self-fixation), but remained able to orient and adjust its behavior towards

218 a partner resembling itself. Social isolation cannot prevent proprioceptive feedback that

219 can complete the visual information that an animal cannot assess without a mirror (Vidal,

220 1975). It has been acknowledged for a long time that experimentally isolated animals are

221 indeed never isolated from themselves (Lehrman, 1953).

222 In interspecific brood parasites, however, early social learning could lead to species

223 recognition errors because young are reared among heterospecifics. In an experiment,

224 feather color of hand-reared fledglings of the parasitic brown-headed cowbird (Molothrus

225 ater) was manipulated. Juvenile cowbirds approached more quickly and associated

226 preferentially with individuals that were colored similarly to themselves (Hauber et al.,

227 2000). This result eliminates the possibility that their recognition template was genetically

228 determined. 
232 Mirror-induced self-directed behavior has been studied in several species of birds. Most of 233 the species tested so far failed to show self-directed behavior in front of their mirror-image.

234 They have been tested either in the wild (chickadees Parus atricapillus, Censky \& Ficken, 235 1982; glaucous-winged gulls Larus glaucescens, Stout et al., 1969) or in the laboratory in 236 captivity (Blue grouse Dendragapus obscurus, Stirling, 1968; budgerigars Melopsittacus 237 undulatus and house sparrows Passer domesticus, Gallup \& Capper, 1970; a kea Nestor 238 notabilis, Diamond \& Bond, 1989; zebra finches Taeniopygia guttata, Ryan 1978; cedar 239 waxwings Bombycilla cedrorum and Juncos Junco hyemalis, Andrews, 1966; Lovebirds 240 Agapornis roseicollis, Delsaut \& Roy, 1980; African Grey Parrot Psittacus erithacus: 241 Pepperberg et al., 1995; Jungle Crow Corvus macrorhynchos: Kusuyama et al., 2000; Java 242 Sparrow Padda oryzivora: Watanabe, 2002; New Caledonian Crow Corvus moneduloides: 243 Medina et al., 2011; Jackdaw Corvus monedula: Soler et al., 2014). Many of them respond 244 to thei self-image with social behaviour, i.e. treating the mirror-image as if it were a 245 conspecific. Some bird species exhibit aggressive behavior in the presence of a mirror 246 while others exhibit courtship displays. A Flamingo (Phoeniconais minor) flock exhibited 247 marching displays in front of mirrors (Pickering \& Duverge, 1992). Some bird species such 248 as house sparrows, parakeets and zebra finches exhibit a preference for mirror image 249 stimulation over visual access to a conspecific (Gallup \& Capper, 1970; Ryan, 1978). This 250 preference was shown in the absence of auditory cues. The authors hypothesized that the 251 mirror image could be perceived as a supernormal stimulus since the mirror image would 252 always be both predictable and compatible with the animal's behavior. Mirrors are often 
253 used as a social substitute to reduce stress in highly social birds, such as starlings (Sturnus

254 vulgaris, Henry et al., 2008) and zebra finches, kept in social isolation for laboratory

255 experiments. Female pigeons (Columba livia) would ovulate when exposed to her own

256 reflection in a mirror (Matthews, 1939). It is noteworthy that the length of exposure and

257 size of the mirror vary greatly across these studies. So far, MSR capacity using an adapted

258 version of the experimental procedure developed by Gallup (1970) has been found only in

259 one bird species, the magpie (Prior et al., 2008; Figure 3). The authors used a sticker as a

260 mark that was stuck under the beak, in the throat area, outside the magpies' visual field.

261 Two magpies out of five were capable of removing the sticker by scratching with their foot

262 in mirror-present sessions. The results obtained in magpies have important biological and

263 cognitive implications because the fact that magpies were able to pass the mark test means

264 that mirror self-recognition evolved independently in the magpie and great apes (which

265 diverged 300 million years ago) and that the neocortex (which is not present in the bird's

266 brains as mentioned before) is not a prerequisite for MSR as previously believed (Prior et

267 al., 2008). Using the same experimental procedure, Soler and colleagues (2014) failed to

268 show MSR in jackdaws: they showed mark-directed behavior in the mirror but also in the

269 no-mirror condition. Moreover, the authors pointed out potential methodological problems

270 with the study on magpies. According to them, magpies might have detected the sticker

271 using tactile sense through feather sensitivity. They suggest to use more appropriate

272 marking methods for future avian marking tests such as using paint that does not

273 agglomerate the feathers or, at least allows for the perfect separation of feathers when dried,

274 for instance typing correction fluid. However, as two of the magpies showed significantly

275 more mark-directed behavior when tested in front of a mirror than in the absence of a 
276 mirror, tactile sense cannot be the sole explanation for their mark-directed behavior.

277 Another interesting result from the magpie and the jackdaw studies is that in both 278 experiments the birds showed self-contingent behavior (i.e., they moved their head or the

279 whole body back and forth in front of the mirror in a systematic way). In the magpie study,

280 the 3 birds that showed self-contingency behavior also showed mark-directed enhanced

281 behavior in the mark test (this was significant for two of them).

282 Mirror studies were also conducted in two other corvid species, namely the jungle crow

283 (Kusayama et al., 2011) and the New Caledonian crow (Medina et al., 2011). New

284 Caledonian crows, but not jungle crows, had the possibility to explore behind the mirror as

285 in the magpie study. No self-contingency behavior was reported for the jungle crows; the 286 birds may not have received enough mirror experience though, since they had only 3 287 sessions of 25 minutes with a vertical mirror, and the same amount of time with a horizontal 288 mirror. Exposure to mirrors was also very limited in the study on New Caledonian crows, 289 only 3 sessions of 10 minutes. The authors reported that they did not observe self290 contingent behavior, but that 3 juvenile crows (out of 10 birds) reacted to their mirror image 291 by repeatedly performing "peekaboo" behavior. Such behaviors could in fact be a kind of 292 self-contingent behavior, and were also observed in one of the two young grey parrots 293 tested by Pepperberg et al. (1995). The other grey parrot also showed a kind of self294 contingent behavior: in 3 sessions out of 15 , she put a foot against the mirror and placed 295 her head as to provide a simultaneous view of her foot and its mirror image. African grey 296 parrots (Pepperberg et al., 1995) and New Caledonian crows (Medina et al., 2011) also 297 showed the ability to use a mirror to locate hidden food. 
298 In many studies, the mirror was presented in a vertical position. The horizontal mirror 299 image may mimic a reflection from a water surface and it would be more natural for the 300 bird to see the image as its own. On the other hand, vertical images are more natural than

301 the horizontal ones if they are seen as images of conspecifics. Indeed, an upright mirror

302 was more effective for evoking social aggressive behavior than a horizontally placed mirror

303 (Kusayama et al., 2000; Pepperberg et al., 1995).

304 To sum up, self-contingent behavior was observed (at least in some individuals) in 3 out 305 of 4 studies in corvids and in the one study with parrots. Only two mark tests have been 306 conducted in birds: the magpie study, in which some of the birds passed the test, and the 307 jackdaw study, which was not conclusive, since the birds showed mark-directed behavior 308 in both the mirror and no-mirror conditions, probably because they sensed the sticker on 309 their feathers. Therefore, although more experiments are needed (particularly conducting 310 mark tests with a design ensuring that tactile cueing is not possible) these data are very 311 promising and hint to some ability for MSR in corvids and parrots. These abilities would 312 be consistent with high performance in these birds in tasks related to theory of mind 313 (Bugnyar et al., 2016; Dally et al., 2006; Emery \& Clayton, 2001; Péron et al., 2010; 2011).

314 It is extremely crucial to check whether self-directed behavior in birds represents a 315 spontaneous response to seeing their own body in the mirror. Pigeons were successfully 316 trained to peck at a spot on their bodies that could only be seen with the aid of a mirror 317 (Epstein et al., 1981). Thompson \& Contie (1994) failed to replicate these results although 318 the exact details of the training procedure had not been documented and training could 319 have been a crucial factor in obtaining positive results. Indeed, Uchino and Watanabe 320 (2014) recently revisited self-recognition in pigeons using a similar procedure as Epstein 
321 and collaborators. They observed that after extensive training with food reinforcement, two

322 pigeons spontaneously integrated the learned self-directed and mirror-use behavior and

323 displayed self-directed behavior in a mark test. In a previous experiment, the authors

324 trained pigeons to respond to live video images of themselves and not to respond when

325 they viewed prerecorded videos (Toda \& Watanabe, 2008). Pigeons' discrimination of self-

326 movies was based on the temporal contiguity between their behavior and visual feedback

327 since their relative response rate to delayed presentation of live self-movies gradually

328 decreased as the temporal discrepancy between their own behavior and the corresponding

329 video increased (Toda \& Watanabe, 2008). These results suggest that the visual properties

330 of self-image are not the primary cue for self-recognition, and the visual-proprioceptive

331 contingency between a subject's action and the corresponding visual scene reflected in a

332 mirror might be an essential component. If so, subjects might not require complex cognitive

333 and social abilities to discriminate self from others (Toda \& Watanabe, 2008). That said,

334 pigeons need extensive training for this form of self-recognition which contrasts drastically

335 with humans and other species that do not need such training. This is the case with the

336 magpies that exhibited self-related behavior in front of a mirror after a rather short

337 cumulative exposure time and without being specifically trained to do so (Prior et al., 338 2008).

340 3. Exposure of a bird to its own smell

342 In several petrel species of burrow nesters, the burrow olfactory signature is important for

343 homing. Using a T-maze experiment, de Léon et al. (2003) showed that European storm 
344 petrel chicks (Hydrobates pelagicus) are able to recognize their own odor and that this odor 345 leads them back to the nest.

346 Using a similar kind of maze experiment, it was shown that Antarctic prions (Pachyptila

347 desolata) preferred their own odor when presented against an odorless blank cotton, thus

348 demonstrating the bird's capacity to perceive self-odor (Bonadonna \& Nevitt, 2004).

349 Further work on this species and blue petrels (Halobaena caerulea) demonstrated that these

350 birds could discriminate between their own and their mates' odors. They are attracted by

351 their mate's odor, and they prefer the odor of a conspecific bird to their own (Bonadonna

352 \& Nevitt, 2004; Mardon \& Bonadonna, 2009). Such behavior could be related to kin

353 recognition and inbreeding avoidance (Bonadonna, 2009). Another study has shown that

354 Humboldt penguins (Spheniscus humboldti) preferred unfamiliar non-kin odors over 355 unfamiliar kin odors (Coffin et al., 2011). This study provided evidence of odor-based kin 356 discrimination in a bird, probably through a mechanism of phenotype matching. Olfactory 357 preferences may vary with age and/or social context so that self-odor avoidance may be 358 developed only at sexual maturity.

359 Although olfaction was often believed to be unimportant in songbirds, zebra finch and

360 Bengalese finch (Lonchura striata) females (but not males) prefer the odor of their own 361 nest over a foreign conspecific nest (Krause \& Caspers, 2012). Young zebra finches also 362 prefer the odor of their natal nest over a foreign nest odor (Caspers \& Krause, 2010). This 363 preference is learned very early, in the $48 \mathrm{~h}$ after hatching, or maybe even before hatching, 364 as shown by cross fostering experiments (Caspers et al., 2013, Krause et al., 2012).

365 As discussed above, some birds can recognize their own odor, but this could be based on a 366 simple familiarity rather than on a concept of self. To separate between these alternatives 
367 is not easy. Some matching-to-sample experiments could be conducted in which a bird

368 would have to match the odor of different conspecifics, including itself, to vocalizations or

369 images. However, to solve this task, the bird would have to identify his own odor but also

370 his own vocalizations or image. Some priming experiments (exposure to one stimulus to

371 influence the response to another stimulus) using different modalities could also be

372 informative in this respect.

\section{4. Exposure of a bird to its own vocalizations}

376 As mentioned before, birds are of particular interest regarding vocalizations since many

377 species (mostly oscine songbirds representing about half of all bird species) exhibit vocal

378 production learning, which is the capacity to imitate sounds from the environment, mainly

379 those from the social environment produced by conspecifics. In other, non-vocal learning

380 species, such as columbiforms (e.g. pigeons, doves) and galliforms (e.g. chickens, quails),

381 the structure of vocalizations is under a strong genetic determinism despite some

382 rudimentary vocal plasticity reminiscent to that described recently in non-human primates

383 (Derégnaucourt et al., 2009). Some vocal learners, like starlings and canaries, are able to

384 learn new songs throughout their lives, sometimes during limited periods of time during

385 the year, while others, like zebra finches, can only learn to imitate a song model during a

386 sensitive period in the first year of life (Brainard \& Doupe, 2002). Some species, such as

387 the zebra finch, produce a single (short duration) song while others, such as the nightingale

388 (Luscinia megarhynchos), possess a song repertoire composed of hundreds of different 389 song types (Catchpole \& Slater, 2008). 
392 To our knowledge, all experiments in the wild concern oscine songbirds. The first 393 experiments using the Bird's Own Song (BOS) aimed at understanding the function of 394 different songs in the bird's repertoire (Great Tit Parus major: Krebs et al., 1981; Brémond, 395 1968). Some studies investigated more subtle aspects such as song timing during vocal 396 exchanges in nightingales (Hultsch \& Todt, 1982), European blackbirds (Turdus merula; 397 Todt, 1970, 1975, 1981; Wolffgramm \& Todt, 1982) and great tits (Weary et al., 1990). In 398 most of the cases, the broadcast of the BOS has been used as a control in experiments of 399 simulated territorial intrusion with the idea that the birds could use their BOS as a reference 400 against which other songs could be evaluated (Mc Arthur, 1986). In such experiments, 401 birds exhibit different behavioral responses that could be measured such as their latency to 402 react, their approach to the loudspeaker, the number of songs produced and the acoustic 403 similarity between the songs produced and the song broadcast ('song matching').

404 In some species, behavioral responses to song playbacks are maximal when the song 405 broadcast is the BOS. For example, in great tits (Falls et al., 1982), western meadowlarks 406 (Sturnella neglecta; Falls, 1985) and song sparrows (Stoddard et al., 1992), song matching 407 was maximal following broadcast of the BOS in comparison with neighbor and stranger 408 songs. In other studies, the BOS produced an intermediate response strength falling 409 between that elicited by the songs neighbors and strangers (ovenbirds Seirus aurocapillus:

410 Weeden \& Falls, 1959; white-throated sparrow Zonotrichia alhicollis: Brooks \& Falls, 411 1975; swamp sparrows Melospiza georgiana: Searcy et al., 1981; red-winged blackbirds 412 Agelaius phoeniceus: Yasukawa et al. 1982).The majority of birdsong research concerns 
413 male song, but females from many oscine songbird species also sing (Odom et al., 2014).

414 In the red-winged blackbird, females gave statistically similar responses to playback of

415 BOS and stranger songs (Beletsky, 1983).

416 In song sparrows, results differ between different studies and this highlights the necessity

417 to take into account the methodological aspects of the playback procedure, the response

418 measures and the statistical treatment of the data. Some studies have shown that the

419 response of male song sparrows to the BOS is not different than the response to a stranger

420 song, both in terms of aggression (approach to the speaker; Searcy et al., 1981) and song

421 matching (Stoddard et al., 1992). In contrast, in the only study conducted with the goal to

422 demonstrate auditory self-awareness in birds, Mc Arthur (1986) observed that the territorial

423 response was minimal during the broadcast of the BOS and that the strength of the

424 territorial response was inversely correlated with the similarity of the stimulus song to the

425 BOS. Nevertheless, song matching was also higher for the BOS than for a stranger song

426 acoustically dissimilar to the BOS. Some of these results were not statistically significant.

427 It is also worth mentioning that these studies were done before the advent of the

428 multivariate-measure approach (such as principal component analysis) that became a

429 standard in the design of playback experiments since the 90’s (Mc Gregor, 1992).

430 How can we interpret these results? In the case when the bird exhibits a strong response, it

431 may be that he perceived the BOS as a fully shared stranger song. One's own sounds might

432 be perceived as different since the normal bone conduction that is present when emitting a

433 sound is absent from the playback sound. In the same way the human voice sounds strange

434 when heard from a tape, a bird could react to his BOS as though it were produced by a

435 stranger. Response to BOS in song sparrows is similar to response to stranger song both in 
436 terms of matching (Stoddard et al. 1992) and aggression (Searcy et al. 1981 but see Mc

437 Arthur, 1986), and another study suggest that there is no voice recognition in this species

438 (Beecher et al., 1994). However, a bird could also recognize his BOS and react strongly

439 because he is surprised to hear himself. He would approach the loudspeaker or even sing

440 in order to investigate what is happening; therefore, very detailed description of the bird's

441 behaviors would be needed to discriminate between a purely territorial response and a

442 surprised response.

443 When the response to the playback of the BOS is weak, auditory self-awareness could be 444 suggested but there are also other alternative hypotheses (Mc Arthur, 1986). Habituation 445 and familiarity could be involved. One would expect a male to hear his own song more 446 often than that of any of his neighbors. If a male's perception of his own song as he sings 447 it is the same as his perception of its BOS playback (one can only speculate about the 448 degree to which a bird's skull distorts the perception of its song as it is sung), a weaker 449 response to BOS than to neighbor song would be predicted. For reasons already mentioned 450 above, the results obtained by Mc Arthur (1986) and his interpretation of the data have 451 been questioned (Suarez \& Gallup, 1987; Mc Arthur 1987), and most results obtained in 452 song sparrows show that birds consider BOS as stranger songs.

453 Brooks and Falls (1975) provide an explanation for an intermediate response to the 454 playback of BOS (responses measuring between those to stranger and to neighbor songs).

455 During the broadcast of a song in the territory of a focal bird, song activity from his 456 neighbors is sometimes observed and this vocal activity could affect the behavioral 457 response of the focal bird. During the broadcast of a stranger song, the strong response of 458 a focal bird could be enhanced by the strong response of his neighbors. During the 
459 broadcast of his BOS, his neighbors should recognize him and act accordingly by singing 460 less. This low activity might affect the response of the focal bird. But the BOS may also 461 sound intermediate in terms in familiarity: less familiar than a neighbor song because of 462 the bone distortion, but more familiar than a completely stranger song.

463 The different reactions to the BOS playback are also probably linked to the different socio464 ecological aspects of the different species that were tested. During song playback, males 465 of some species engage in counter-singing: they produce the song that best resembles the 466 playback song (Bremond, 1968; Falls et al., 1988). Indeed, many species of oscine 467 songbirds often engage in copying and matching sounds through which they address each 468 other. Depending on the context, they could use either song type matching, (producing the 469 same song they hear) or repertoire matching (producing a shared song type while avoiding 470 singing the same song type). Playback of the BOS have been used extensively in several 471 experiments on matching in song sparrows (Akçay et al., 2011, 2013, 2014; Anderson et 472 al. 2005; Searcy et al., 2013; Stoddard et al., 1992). For example, song sparrows use song 473 type matching when defending their territory against an unknown male, but avoid it when 474 interacting with known neighbors with whom they use more subtle repertoire matching 475 (Beecher \& Campbell, 2005). Repertoire matching may allow addressing a neighbor in a 476 more affiliative or neutral way. For example, song sparrows, western meadowlarks and 477 great tits do not type-match a neighbor's song but do the BOS or a stranger's song (Falls, 478 1985; Falls et al., 1982; Stoddard et al., 1992). In some species such as the great tit, if the 479 theme broadcast is absent from the bird's repertoire, it will reply with the theme closest in 480 structure within its own repertoire (Krebs et al., 1981). This form of categorization suggests 481 that there is an auditory reference to which the stimulus is compared before production 
occurs. Such a reference is the result of different influences, particularly learning. More

483 recently, playback of the BOS brought to light a turnover in repertoire composition over a

484 relatively short period in great tits (Franco \& Slabbekoorn, 2009).

485 Another hypothesis was that the BOS could be used as a reference in localizing the emitter:

486 degradation of a song over distance may be used as a cue if the male has his own, 487 undegraded rendition of the song to use as a standard (Morton, 1982). Mc Gregor \& Krebs 488 (1984) have shown that great tits respond less strongly to degraded than to undegraded 489 song? not only if they are sung by the birds themselves (BOS) but also if they are produced 490 by neighbors. This result suggests that birds do not necessarily need to have a song in their 491 own repertoire to use sound degradation as a distance cue but rather to be familiar with the 492 song broadcast. This finding that birds can assess the degree of degradation of songs that 493 they do not sing, supports the idea that birds learn more songs than they sing.

494 Altogether, these experiments have shown that familiarity and acoustic similarity with the 495 BOS are taken into account by the focal bird to provide an appropriate behavioral response 496 (song matching, approach to the loudspeaker) during song broadcast.

\subsection{Experiments in the laboratory}

500 The hypothesis that the BOS is used as a reference against which other males' songs are 501 evaluated was first proposed by Hinde (1958) based on his experiments with hand-reared, 502 tutored chaffinches (Fringilla coelebs). He tutored young males with abnormal songs, 503 which they learned and later sang as adults. When the adults heard normal chaffinch songs 504 and their abnormal BOS, they produced more songs in response to the abnormal BOS. 
505 Similarly, adult zebra finches (Taeniopygia guttata) express a robust behavioral preference

506 for the playback of their BOS compared with conspecific male song in a phonotaxis

507 experiment (Remage-Healey et al., 2010). However, the tutor song is a stronger stimulus

508 than the BOS: finches exposed either passively or through operant conditioning to the tutor

509 song during development preferred the training song over a novel song as well as over their

510 BOS as adults (Adret, 1993). Using operant conditioning, it was shown that males trained

511 to discriminate between their own song and another song from their aviary reached

512 criterion in a fewer number of trials than males that had to discriminate between songs

513 from their own aviary, with the most training required by males discriminating between

514 songs they had not heard before (Cynx \& Nottebohm, 1992). While most studies

515 investigated songs in oscine songbirds, it is worth mentioning that the 'autogenous

516 reference' could be also used in non-vocal learner species through self-referent phenotype

517 matching. For example, in a two-choice experiment, neonate chicks (Gallus domesticus)

518 exhibited a preference for a speaker broadcasting a maternal call with acoustic features

519 resembling those of the bird's own twitter rather than a speaker broadcasting a maternal

520 call with acoustics dissimilar to their own twitter (Guyomarc'h, 1973). Similarly, chicks

521 raised in mixed flocks of two varieties, when tested in a Y-maze, learn to go to chicks of

522 their own variety more readily than to those of the other variety (Howells \& Vine, 1940).

523 Besides genetic influences, it is also plausible that the chick's experience with its own

524 chirping could be used as a source of differential learning (Schneirla, 1946).

525 At the neural level, the earliest attempts to record singing-related activity in the brain of 526 freely behaving oscine songbirds (canaries and white-crowned sparrows) detected 527 increased activity not only during singing but also when the BOS was broadcast through a 
528 speaker (Mc Casland \& Konishi, 1981). This paradigm, used in more than one hundred

529 studies so far, could permit to look for the neural template that determines the BOS.

530 Songbirds have specialized, discrete brain regions for song production and learning (Figure

531 4). The Song Motor Pathway (SMP) is involved in song production and certain aspects of 532 song learning, and the Anterior Forebrain Pathway (AFP) that connects with the motor 533 pathway, is essential for sensorimotor learning and adult song plasticity. These two 534 pathways together are usually called the 'song control system' (Brainard \& Doupe, 2002).

535 The sensorimotor nucleus HVC (used as a proper name) which belongs to the SMP was 536 the first song nucleus in which song-selective neurons were observed (Mc Casland \& 537 Konishi, 1981). Most neurons from the HVC that are responsive to song playback are 538 highly selective for the BOS, firing more to forward auditory playback of the BOS than to 539 reverse BOS or conspecific songs (Margoliash, 1983, 1986; Margoliash \& Konishi, 1985; 540 Mooney, 2000).

541 In contrast, field L neurons from the primary auditory regions, which are presumed to be a 542 source of auditory input to HVC, do not exhibit selectivity for BOS (Margoliash, 1986; 543 Boumans et al., 2008). These observations implicate song (motor) learning in shaping the 544 response properties of HVC but not of auditory neurons.

545 It has been proposed that HVC auditory neurons may contribute to a bird's ability to 546 discriminate among conspecific songs by acting as an 'autogenous reference' during the 547 perception of those songs (Margoliash, 1986). During the process of song acquisition, 548 auditory neurons in the song control system are shaped to respond best to the BOS 549 (Margoliash, 1983; Doupe \& Konishi, 1991). 
550 This pattern of self-responsiveness is even found in adult birds raised without a tutor 551 indicating that self-experience is a critical factor in shaping BOS-selectivity (Kojima \& 552 Doupe, 2007). Furthermore, BOS-selective auditory responses in HVC and the AFP 553 emerge as sensorimotor learning progresses (Volman, 1993; Doupe, 1997; Solis \& Doupe, 554 1999; Nick \& Konishi, 2005a,b).

555 Using lesions both at the central and peripheral levels, the development of the selectivity 556 for the BOS and its neural template could be investigated (Remage-Healey et al., 2010; 557 Roy \& Mooney, 2007).

558 Male finches muted during the sensitive period for song learning responded to playbacks 559 at chance levels as adults, showing no preferences for individual conspecific songs. These 560 results suggest that the acquisition of the BOS may contribute to the perceptual processing, 561 recognition, or discrimination of different conspecific songs (Pytte \& Suthers, 1999). This 562 experiment and others support a hypothesis which is an avian parallel to the motor theory 563 of speech perception in humans (Williams \& Nottebohm, 1985). This theory proposes that 564 speech is perceived not just as a sound but as a series of articulatory gestures (Liberman \& 565 Mattingly, 1985).

566 Many techniques have been applied to investigate the functional organization of the song 567 system. Although single-cell electrophysiology has been the most successful, other 568 techniques such as gene expression and brain imaging have helped to decipher the neural 569 coding of the BOS (Kimpo \& Doupe, 1997; Boumans et al., 2008; Van der Kant et al., $570 \quad 2013)$.

571 Taken together, these results suggest that BOS-selective neurons in oscine songbirds could 572 provide an 'error signal' that promotes changes in song production when a mismatch is 
573 detected between auditory feedback from self-song and the memorized song template, and

574 could thus have a role in both song learning and maintenance (but see Leonardo, 2004). A

575 second function might be the perception of conspecific song. These functions are not

576 necessarily mutually incompatible. They could also be at play in non-songbird species. For

577 example, the influence of auditory feedback on sexual development has also been

578 extensively studied in a non-vocal learner species, the ring dove (Streptopelia risoria). In

579 this species, courtship is initiated by males. Males' coos (the equivalent of song in oscine

580 songbirds) is an integral feature of the courtship. When the female is motivated, she

581 produces her own 'nest coos' in response to the male's coos. Several experiments in intact,

582 muted, and deafened female doves have shown that a female's own nest coos affect her

583 endocrine state (Cheng \& Durand, 2004). For example, playback of the female's own coos

584 was the most effective stimulus for her follicular development, but playback of other

585 female coos was also more effective than playback of male song.

586 Most studies of the song selectivity of HVC neurons have been performed in the zebra

587 finch, a species that sing a single song (Catchpole \& Slater, 2008). Studies in other songbird

588 species that sing several song types or longer song have expanded this picture and provided

589 new insights into the neural coding of song in the HVC (Nakamura \& Okanoya, 2004;

590 George et al., 2005; Nealen \& Schmidt, 2006; Alliende et al., 2013). For example, the

591 swamp sparrow is a species that sings $2-5$ simple song types, each consisting of the

592 repetition of a single syllable. Some neurons in HVC exhibit both motor-related activity

593 and auditory responses to a playback of a BOS. As such, these neurons are reminiscent of

594 the mirror neurons discovered in the monkey brain (Prather et al., 2008). 
595 Selectivity of HVC neurons is modulated by the behavioral state of the animal, and 596 interspecific differences have been observed (Margoliash \& Schmidt, 2010). For example, 597 in the zebra finch, neurons with responses to BOS playback in anaesthetized or sleeping 598 animals do not always show these responses when finches are awake, indicating that 599 auditory responses to sounds are 'gated' by the behavioral state of the bird and little or no 600 auditory-evoked activity is detectable in the HVC or the AFP during periods of 601 wakefulness (Cardin \& Schmidt, 2003). In contrast, song-evoked auditory responses have 602 been detected in song system of awake sparrows, starlings, canaries and Bengalese finches, 603 indicating that the 'gate' between the auditory and song systems remains open in these 604 species (McCasland \& Konishi, 1981; George et al., 2005; Margoliash, 1986; Nealen \& 605 Schmidt, 2006; Prather et al., 2008; Fujimoto et al., 2011).

606 In the zebra finch, timing and structure of neural activity elicited by the playback of the 607 BOS during sleep matches activity during daytime singing in many brain nuclei of the song 608 control system such as the HVC and the RA (Dave \& Margoliash, 2000; Hahnloser et al., 609 2002). Additionally, 'spontaneous' activity of these neurons during sleep matches their 610 sensorimotor activity, a form of song 'replay.' These data suggest a model whereby 611 sensorimotor correspondences are stored during singing but do not modify behavior, and 612 off-line comparison (e.g., during sleep) of rehearsed motor output and predicted sensory 613 feedback is used to adaptively shape motor output (Derégnaucourt et al., 2005; Margoliash $614 \&$ Schmidt, 2010). To conclude, the perception of the BOS and to some extent of the self 615 is affected by the behavioral state and can also be addressed in sleeping birds. 


\section{5. Use of learned signals as individually specific labels}

620 It is well known, in both vocal and non-vocal learners that animals can recognize a

621 conspecific based on acoustic cues. Addressing of specific individuals in a communication

622 network can be achieved by vocal labeling, where a specific vocalization is linked to a

623 specific individual (Balsby et al., 2012). In captivity, animals can be easily trained to

624 associate a sound, often a human spoken word, with a personal reward such as food or care.

625 For example, using a combination of classical and operant conditioning procedures, pigs

626 living in a group can be trained to enter a feeder only after an individual acoustic signal

627 has been presented. This call feeding procedure minimizes queuing and thereby reduces 628 aggression, stress and injuries associated with feeding (Manteuffel et al., 2011). In the wild, 629 there is evidence that bottlenose dolphins recognize their own vocal signature (King \& 630 Janik, 2013). In birds, some species of parrots have been found capable of using arbitrary, 631 learned signals to label or name objects in experimental studies (Pepperberg, 1981). In

632 captivity, parrots can learn to pronounce their own name and to respond to it more than to 633 the name of other individuals (Bovet, Giret \& Péron, unpublished obs.), but, as in the case 634 of pigs cited above, this could be the result of a simple conditioning effect that is not 635 necessarily linked to self-awareness. Researchers working with ravens (Corvus corax) can 636 also easily get the bird's attention by calling its name (Bugnyar et al., 2016). One raven 637 raised in captivity in isolation who was named Goliath would produce its name when his 638 caretaker would enter in the room (Gwinner, 1964). There is also evidence that a kind of 639 naming is also present in the natural communication system of some bird species. For 640 example, spectacled parrotlets (Forpus conspicillatus) use contact calls to refer to a social 
641 companion and thus label or 'name' their conspecifics (Wanker et al., 2005; Figure 5).

642 Such labelling could help capturing the attention of and further interaction with a particular

643 individual in the social group, similarly to humans calling out the name of an associate at

644 a noisy social gathering. It is possible that these contact calls used as labels or 'names'

645 could be imitations of the addressee's calls but that hypothesis has not been tested yet in

646 this species (Bradbury \& Balsby, 2016). Such imitation have been observed in orange-

647 fronted conures (Aratinga canicularis). Conures can imitate contact calls almost

648 immediately upon hearing them (Balsby \& Bradbury, 2009). In this fusion/fission species

649 that is non-territorial and that lives in small groups, vocal matching is observed in the wild

650 prior to flock fusion and might represent some form of negotiation (Balsby \& Bradbury,

651 2009). Orange-fronted conures can use imitation of contact calls to address specific

652 individuals of a flock (Balsby et al., 2012). The authors argue that the fission-fusion flock

653 dynamics of many parrot species has been an important factor in evolving conures' and

654 other parrots' exceptional ability to imitate (Bradbury \& Balsby, 2012).

655

656 6. Conclusion and future directions

657

658 Exposing an animal to its own image, smell or vocalizations experimentally has helped us 659 understand how individuals process social information. Since the perception of self can be 660 achieved using different sensory modalities, it would be of interest to investigate whether 661 each modality controls a different level of self or if these different levels are linked to each 662 other in order for an individual to build an integrative and unified template of self. In many 663 species, subjects are able to match the voice of a familiar conspecific to its image. For 
664 example, large-billed crows are sensitive to identity congruence between the visual 665 presentation of a group member and its contact call (Kondo et al., 2012), and grey parrots 666 can visually and acoustically discriminate conspecifics (Giret et al., 2009). Therefore, 667 maybe a concept of self could be cross-modal. In adult humans, priming experiments 668 suggest that the brain processes information about the self in highly integrated ways: being 669 exposed to one's own body odor and a visual or auditory presentation of one's name 670 facilitated self-face recognition in a reaction time task (Platek et al., 2004). The perception 671 of emotion through cross-modal sensory integration enables faster, more accurate and more 672 reliable recognition (Yuval-Greenberg \& Deouell, 2009). As mentioned before, matching673 to-sample experiments using a bird's own odor, vocalizations and/or image can be used to 674 study self-recognition. It would be interesting to present birds their own odor or 675 vocalizations and see whether they facilitate mirror self-recognition, or to train them to 676 give a particular response to their own image,and see whether priming effects would be 677 found by presenting their odor or vocalization or names simultaneously. Of course, training 678 birds to respond to their own vocalizations or odor and then priming them with other 679 modalities could be done too. Such aspects and those linked to the formation of cross680 modal individual recognition through experience and social interactions could be easily 681 studied in captive populations of birds.

682 As in other animals, the concept of self in birds can be addressed through two main areas 683 of research: self-referent phenotype matching and self-awareness.

684 Self-referent phenotype matching has been demonstrated in birds using visual stimuli and 685 it is likely that it is at play when birds discriminate among different conspecifics based on 686 acoustic cues. The major histocompatibility complex (MHC), which plays a central role in 
687 disease resistance and immune defense, represents a special case of self-referent phenotype 688 matching, and it is also involved in olfactory mate choice decision in several vertebrate 689 taxa including birds (Caro et al., 2015).

690 Self-awareness is the most fascinating aspect of self-recognition information and it has

691 been proposed to be an important component of the Theory of Mind. As mentioned before, 692 most birds consider their own reflection as another individual. Corvids and parrots showed 693 self-contingent behaviour in front of a mirror, but only magpies seem to recognize 694 themselves in a mirror without extended exposure to the mirror or training (Prior et al., 695 2008).

696 The assumption that self-recognition is an indicator of self-awareness appears to be valid, 697 since to show spontaneous self-recognition (without specific training), an animal needs to 698 be sufficiently self-aware to understand how it looks from another perspective (Anderson $699 \&$ Gallup, 2015) and, as highlighted above, this ability is often correlated with other signs 700 of self-awareness. On the other hand, the failure of an organism to respond appropriately 701 to mirrors is more difficult to interpret and does not necessarily imply the absence of self702 awareness (Povinelli, 1987). Therefore, birds may be self-aware, and show it in other 703 experiments, without exhibiting MSR. First, the mirror test might not be appropriate for 704 species that consider direct gaze as a threat such as dogs and many species of primates. 705 Unlike primates, birds do not possess facial musculature revealing precise details about 706 their emotional state. However, they can express some of their emotional states with their 707 feathers, and, in birds that possess a crest such as the cockatoo, with their crest movements 708 (Athan, 2010). Animals are usually tested alone but MSR could be obtained more rapidly 
709 if animals were tested with another familiar individual. Indeed, simultaneous exposure to

710 a familiar individual and its reflection in a mirror could facilitate MSR.

711 Second, one should keep in mind that though MSR reflects a crucial step in the emergence

712 of self-recognition, the fully fledged capacity is complex, and comparative, clinical, and

713 developmental studies suggest an overall gradual development of this capacity in animals

714 including humans (Rochat, 2015). Behaviorists have tried to link MSR to conditioning,

715 claiming that the relationship between self and mirror can be learned. As mentioned before,

716 they successfully trained pigeons to locate a spot on the body by using a mirror (Epstein et

717 al., 1981). In the same way, MSR was recently successfully induced in Rhesus monkeys

718 after visual-somatosensory training. Monkeys were trained in front of a mirror to touch a

719 light spot on their face produced by a laser light that elicited an irritant sensation. After 2-

7205 weeks of training, monkeys had learned to touch a face area marked by a non-irritant

721 light spot or odorless dye in front of a mirror (Chang et al., 2015). These experiments do

722 not really prove any self-awareness, however, since the critical issue is whether animals

723 spontaneously connect their reflection with their own body. But it is worth mentioning that

724 in studies performed with birds, mainly adult animals were used, without a precise

725 knowledge of their developmental background although these aspects could be easily

726 monitored in captive populations. Several studies have shown that animals including birds

727 are often exposed to their own reflection for example in the drinking trough and

728 manipulating this reflection can affect their behavior (Salzen \& Cornell, 1968). Therefore,

729 the duration of exposure to their own image is not really known, and mirror self-recognition

730 may be linked to this duration. 
731 In the same way that many bird species interpret their reflection in a mirror as a conspecific,

732 it is likely that they consider playbacks of their BOS as a stranger's song and, as discussed

733 above, this paradigm has been used extensively to study vocal interactions during territorial

734 challenges (Akçay et al., 2011, 2013, 2014). However, even a chimpanzee touching a red

735 spot on his head can be interpreted in different ways (Heyes, 1994), and reactions to

736 playbacks of the animal's own vocalizations are even less easy to interpret in the context

737 of self-recognition (Mc Arthur, 1987). For example, depending on the species, a bird would

738 approach a speaker, produce songs and/or calls and/or remain silent. One possibility would

739 be to use live or delayed auditory feedback. This could give the opportunity to the bird to

740 adjust to the fact that vocalizations produced lived may sound distorted on playback.

741 Moreover, if the animal was capable of auditory self-recognition, not only should it come

742 to distinguish its vocalizations from those of other individuals, but it also ought to respond

743 differentially to unexpected changes or distortions in the playback of its vocalizations that

744 it did not itself produce, akin to the mark test of visual self-recognition (Suarez \& Gallup,

745 1987). Such experiments are challanging to conduct in the wild, but they would be easier

746 to manage with captive populations of birds. In particular, to our knowledge, reactions of

747 corvids or psittacids to the broadcast of their own vocalizations have never been

748 investigated.

749 Studies obtained in oscine songbirds also emphasized the role of experience and 750 development in the BOS recognition. In the case of the zebra finch that produces a short 751 song, neural song replay during sleep has been interpreted as the bird 'dreaming' of his 752 song (Dave \& Margoliash, 2000). Such neural song replay could also be involved in the 753 developmental learning process of this acoustic signal (Derégnaucourt et al., 2005). 
754 To some extent, the voice could be considered as an embodiment of self social contexts,

755 and developmental changes in the voice patterns might enhance the development of

756 consciousness and self-awareness in humans and probably also in other animals. The

757 acoustic parameters of the vocalizations could provide information about personal identity

758 but it could also inform about the internal state of the producer. Like in mammals, stress

759 can induce vocal changes in the vocalizations of birds. For example, in the zebra finch,

760 acoustic parameters of the contact calls are modified following the injection of

761 corticosterone, considered a stress hormone (Perez et al., 2012). Playback experiments

762 have shown that finches can perceive acoustic differences between stressed and non-

763 stressed contact calls. Moreover, in breeding pairs, playback of stressed contact calls from

764 the sexual partner induces an increase of corticosterone (Perez et al., 2015). Also, we do

765 not know to what extent the vocalizations can be transformed without losing information

766 such as the coding of individuality or the emotional content.

767 The role of experience is also important in the context of vocal labeling shown in several

768 species of parrots. The representational use of learned identity labels represents an

769 interesting parallel to humans and the apparent necessity for these vocal labels in

770 maintaining group cohesion may lie at the root of the evolution of complex communication

771 and cognition systems. Experiments in spectacled parrotlets have suggested that these birds

772 have a mental representation of at least their family members because they use different

773 labels for them (Wanker et al., 2005). In this domain, many interesting questions still

774 remain unanswered: how would a bird react when the vocal label (call of a family member)

775 is produced? Would it affect his behavior if this familiar individual was absent or present? 
776 Field studies provide interesting tracks for future research in this domain. As previously

777 mentioned, some experiments with broadcast of the BOS in the male's territory suggest

778 that its reactions could be affected by the reaction of its neighbors (Brooks \& Falls, 1975).

779 Taking advantage of recent technological developments that enable both the vocal (Ter

780 Maat et al., 2014) and spatial (Farine et al., 2015) tracking of different individuals in a

781 social network, it would be of interest to monitor not only the behavior of a target individual

782 during song broadcast in its territory but also those of its different neighbors.

783 Finally, knowing more about sentience and awareness in animals could influence our

784 decisions about our obligations to them (Broom, 2010). Several species of birds are raised

785 in both poultry farms for meat and egg production, and research facilities. Self-

786 consciousness matters from an ethical point of view since it can give rise to forms of

787 suffering above the immediate sensations of pain or distress, although understanding and 788 improving animal welfare can be approached without considering animal consciousness 789 (Dawkins, 2012). Thus, the perception of self has numerous implications for basic research, 790 but it may also be important for animal welfare and legislation. 
794 We thank Michel Kreutzer for his valuable comments on an earlier draft of the manuscript.

795 We also thank Olga Fehér for her valuable comments and for reviewing our English

796 manuscript. Two anonymous reviewers provided many helpful suggestions to improve this

797 long review. S.D. is supported by the Institut Universitaire de France (IUF).

\section{References}

801 Adret, P. 1993. Operant conditioning, song learning and imprinting to taped song in 802 the zebra finch. Animal Behaviour 46, 149-159. doi: 10.1006/anbe.1993.1170

803 Akçay, Ç., Tom, M.E., Holmes, D., Campbell, S.E., \& Beecher, M.D. 2011. Sing softly 804 and carry a big stick: signals of aggressive intent in the song sparrow. Animal Behaviour 805 82, 377-382. doi: 10.1016/j.anbehav.2011.05.016

806 Akçay, Ç., Tom, M.E., Campbell, S.E., \& Beecher, M.D. 2013. Song type matching is 807 an honest early threat signal in a hierarchical animal communication system. Proceedings 808 of the Royal Society of London B: Biological Sciences 280, 20122517. doi: $809 \quad 10.1098 / \mathrm{rspb} .2012 .2517$

810 Akçay, Ç., Campbell, S. E., \& Beecher, M.D. 2014. Individual differences affect honest 811 signalling in a songbird. Proceedings of the Royal Society of London B: Biological Sciences 812 281, 20132496. doi: 10.1098/rspb.2013.2496 
813 Alliende, J., Lehongre, K. \& Del Negro, C. 2013. A species-specific view of song 814 representation in a sensorimotor nucleus. Journal of Physiology Paris 107, 193-202. doi: $815 \quad$ 10.1016/j.jphysparis.2012.08.004

816 Amsterdam, B. 1972. Mirror self-image reactions before age two. Developmental 817 Psychobiology 5, 297-305. doi: 10.1002/dev.420050403

818 Anderson, J.R. \& Gallup, G.G. 2011. Which primates recognize themselves in mirrors.

819 PLoS Biology 9, e1001024. doi: 10.1371/journal.pbio.1001024

820 Anderson, J.R. \& Gallup Jr, G. G. 2015. Mirror self-recognition: a review and critique 821 of attempts to promote and engineer self-recognition in primates. Primates $56,317-326$. 822 doi: 10.1007/s10329-015-0488-9

823 Anderson, R.C., Searcy, W.A., \& Nowicki, S. 2005. Partial song matching in an eastern 824 population of song sparrows, Melospiza melodia. Animal Behaviour 69, 189-196. doi: 825 10.1016/j.anbehav.2004.02.019

826 Andrews, E. 1966. Slate-colored junco response to mirror. Bird-Banding 37, 206.

827 Athan, M.S. 2010. Guide to Companion Parrot Behavior. Barron's Educational Series 828 Inc.,U.S.

829 Balsby, T.J., \& Bradbury, J.W. 2009. Vocal matching by orange-fronted conures 830 (Aratinga canicularis). Behavioural Processes 82, 133-139. doi: $831 \quad 10.1016 / j . b e p r o c .2009 .05 .005$

832 Balsby, T.J., Momberg, J.V., \& Dabelsteen, T. 2012. Vocal imitation in parrots allows 833 addressing of specific individuals in a dynamic communication network. PloS one 7, 834 e49747. doi: 10.1371/journal.pone.0049747 
835 Beecher, M.D. \& Campbell, S.E. 2005. The role of unshared songs in singing 836 interactions between neighbouring song sparrows. Animal Behaviour 70, 1297-1304. doi:

837 10.1016/j.anbehav.2005.03.008

838 Bekoff, M. 2001. Observations of scent-marking and discriminating self from others

839 by a domestic dog (Canis familiaris): tales of displaced yellow snow. Behavioural $840 \quad$ Processes 55, 75-79. doi: 10.1016/S0376-6357(01)00142-5

841 Bekoff, M., \& Sherman, P.W. 2004. Reflections on animal selves. Trends in Ecology 842 and Evolution 19, 176-180. doi:10.1016/j.tree.2003.12.010

843 Beletsky, L.D. 1983. Aggressive response to" self" songs by female Red-winged

844 Blackbirds, Agelaius phoeniceus. Canadian Journal of Zoology 61, 462-465. doi: $845 \quad 10.1139 / z 83-062$

846 Bischof-Köhler, D. 2012. Empathy and self-recognition in phylogenetic and 847 ontogenetic perspective. Emotion Review 4, 40-48. doi: 10.1177/1754073911421377

848 Bolhuis, J.J., Okanoya, K., \& Scharff, C. 2010. Twitter evolution: converging 849 mechanisms in birdsong and human speech. Nature Reviews Neuroscience 11, 747-759. 850 doi:10.1038/nrn2931

851 Bonadonna, F. 2009. Olfaction in petrels. From homing to self-odor avoidance. Annals 852 of the New York Academy of Sciences 1170, 428-433. doi: 10.1111/j.1749$853 \quad 6632.2009 .03890 . x$

854 Bonadonna, F. \& Nevitt, G. A. 2004. Partner-specific odor recognition in an antarctic 855 seabird. Science 306, 835. doi: 10.1126/science.1103001

856 Boumans, T., Gobes, S.M., Poirier, C., Theunissen, F. E., Vandersmissen, L., Pintjens, 857 W., Verhoye, M., Bolhuis, J.J. \& Van der Linden, A. 2008. Functional MRI of auditory 
858 responses in the zebra finch forebrain reveals a hierarchical organisation based on signal 859 strength but not selectivity. PLoS One 3, e3184. doi: 10.1371/journal.pone.0003184

860 Bradbury, J.W., \& Balsby, T.J. 2016. The functions of vocal learning in parrots.

861 Behavioral Ecology and Sociobiology 70, 293-312. doi: 10.1007/s00265-016-2068-4

862 Brainard, M.S., \& Doupe, A.J. 2002. What songbirds teach us about learning. Nature 863 417, 351-358. doi: 10.1038/417351a

864 Bremond, J-C. 1968. Recherches sur la sémantique et les eléments vecteurs 865 d'information dans les signaux acoustiques du rouge-gorge (Erithacus rubecula L.). Revue 866 d'Ecologie Terre et Vie 2, 109-220

867 Brooks, R.J \& Falls, J. B. 1975. Individual recognition by song in white-throated 868 sparrows .I. Discrimination of songs of neighbors and strangers. Canadian Journal of 869 Zoology 53, 879-888. doi: 10.1139/z75-101

870 Broom, D.M. 2010. Animal welfare: an aspect of care, sustainability, and food quality 871 required by the public. Journal of Veterinary Medical Education 37, 83-88. doi: $872 \quad 10.3138 /$ jvme.37.1.83

873 Bugnyar, T., Reber, S.A. \& Buckner, C. 2016. Ravens attribute visual access to unseen 874 competitors. Nature Communications 7, 10506. doi: 10.1038/ncomms 10506

875 Burley, N. T., \& Foster, V. S. 2006. Variation in female choice of mates: condition 876 influences selectivity. Animal Behaviour 72, 713-719. doi:10.1016/j.anbehav.2006.01.017 877 Butler, A.B., Manger, P.R., Lindahl, B.I.B. \& Arhem, P. 2005. Evolution of the neural 878 basis of consciousness: a bird-mammal comparison. Bioessays 27, 923-926. doi: $879 \quad 10.1002 /$ bies.20280 
880 Cammaerts, M-C. \& Cammaerts, R. 2015. Are Ants (Hymenoptera, Formicidae)

881 Capable of Self Recognition? Journal of Science 5, 521-532. doi: 10.1093/jisesa/ieu096. $882 \quad 13$

883 Cardin, J. A., \& Schmidt, M. F. 2003. Song system auditory responses are stable and 884 highly tuned during sedation, rapidly modulated and unselective during wakefulness, and 885 suppressed by arousal. Journal of Neurophysiology 90, 2884-2899. doi: $886 \quad 10.1152 /$ jn.00391.2003.

887 Caro, S.P., Balthazart, J. \& Bonadonna, F. 2015. The perfume of reproduction in birds: 888 Chemosignaling in avian social life. Hormones and behavior 68, 25-42. doi: 889 10.1016/j.yhbeh.2014.06.001

890 Caspers, B. A. \& Krause, E. T. 2010. Odor-based natal nest recognition in the zebra 891 finch (Taeniopygia guttata), a colony-breeding songbird. Biology letters, rsbl20100775. 892 doi: $10.1098 /$ rsbl.2010.0775

893 Caspers, B. A., Hoffman, J. I., Kohlmeier, P., Krüger, O. \& Krause, E. T. 2013. 894 Olfactory imprinting as a mechanism for nest odor recognition in zebra finches. Animal 895 Behaviour 86, 85-90. doi:10.1016/j.anbehav.2013.04.015

896 Catchpole, C.K. \& Slater, P.J.B. 2008. Bird Song: Biological Themes and Variations, $8972^{\text {nd }}$ edition. Cambridge: Cambridge University Press.

898 Censky, E.J., \& Ficken, M.S. 1982. Responses of black-capped chickadees to mirrors. 899 The Wilson Bulletin 94, 590-593. doi: 10.2307/4161696

900 Cheng, M.-F. \& Durand, S.E. 2004. Song and the limbic brain. A new function for the 901 Bird's Own Song. Annals of the New York Academy of Sciences 1016: 611-627. doi: $902 \quad$ 10.1196/annals.1298.019 
903 Coffin, H.R., Watters, J.V. \& Mateo, J.M. 2011. Odor-based recognition of familiar 904 and related conspecifics: a first test conducted on captive Humboldt penguins (Spheniscus 905 humboldti). PLoS One 6, e25002. doi: 10.1371/journal.pone.0025002

906 Cynx, J. \& Nottebohm, F. 1992. Role of gender, season, and familiarity in 907 discrimination of conspecific song by zebra finches (Taeniopygia guttata). Proceedings of 908 the National Academy of Sciences 89, 1368-1371.

909 Dally, J.M., Clayton, N.S. \& Emery, N.J. 2006. The behaviour and evolution of cache 910 protection and pilferage. Animal Behaviour 72, 13-23. doi: 10.1016/j.anbehav.2005.08.020 911 Dave, A.S. \& Margoliash, D. 2000. Song replay during sleep and computational rules 912 for sensorimotor vocal learning. Science 290, 812-816. doi: 10.1126/science.290.5492.812 913 Dawkins, M. S. 2012. Why animals matter: animal consciousness, animal welfare, and 914 human well-being. Oxford University Press, USA.

915 de Léon, A., Minguez, E. \& Belliure, B. 2003. Self-odor recognition in European 916 Storm-Petrel chicks. Behaviour 140, 925-933. doi: 10.1163/156853903770238382

917 Dawkins, R. 1982. The extended phenotype: the gene as the unit of selection. Oxford: 918 Oxford University Press.

919 Delsaut, M., \& Roy, J.C. 1980. Auditory and visual stimuli as reinforcers among 920 lovebirds (Agapornis roseicollis). Behavioral and Neural Biology 28, 319-334. doi: $921 \quad 10.1016 / \mathrm{S} 0163-1047(80) 92315-8$

922 Derégnaucourt, S., Mitra, P.P., Fehér, O., Pytte, C. \& Tchernichovski, O. 2005. How 923 sleep affects the developmental learning of bird song. Nature 433, 710-716. doi: $924 \quad 10.1038 /$ nature 03275 
925 Derégnaucourt, S., Saar, S. \& Gahr, M. 2009. Dynamics of crowing development in 926 the domestic Japanese quail (Coturnix coturnix japonica). Proceedings of the Royal Society 927 of London B: Biological Sciences 276, 2153-2162. doi: 10.1098/rspb.2009.0016

928 Diamond, J., \& Bond, A.B. 1989. Note on the lasting responsiveness of a kea (Nestor 929 notabilis) toward its mirror image. Aviculture magazine 95, 92-94.

930 Doupe, A.J. 1997. Song-and order-selective neurons in the songbird anterior forebrain 931 and their emergence during vocal development. Journal of Neuroscience 17, 1147-1167. 932 doi: $270-6474 / 97 / 171147-21$

933 Doupe, A.J. \& Konishi, M. 1991. Song-selective auditory circuits in the vocal control 934 system of the zebra finch. Proceedings of the National Academy of Sciences 88, 1133993511343.

936 Doupe, A.J., Perkel, D.J., Reiner, A., \& Stern, E. A. 2005. Birdbrains could teach basal 937 ganglia research a new song. Trends in Neurosciences 28, 353-363. doi: $938 \quad 10.1016 /$ j.tins.2005.05.005

939 Edelman, D.B. \& Seth, A.K. 2009. Animal consciousness: a synthetic approach. Trends 940 in Neurosciences 32, 476-484. doi:10.1016/j.tins.2009.05.008

941 Emery, N.J. 2006. Cognitive ornithology: the evolution of avian intelligence. 942 Philosophical Transactions of the Royal Society B: Biological Sciences 361, 23-43. doi: $943 \quad 10.1098 /$ rstb.2005.1736

944 Emery, N.J. \& Clayton, N.S. 2001. Effects of experience and social context on 945 prospective caching strategies by scrub jays. Nature 414, 443-446. doi: $10.1038 / 35106560$ 946 Emery, N.J. \& Clayton, N.S. 2004. The mentality of crows: convergent evolution of 947 intelligence in corvids and apes. Science 306, 1903-1907. doi: 10.1126/science.1098410 
948 Epstein, R., Lanza, R.P. \& Skinner, B.F. 1981. "Self-awareness" in the Pigeon. Science 949 212, 695-696. doi: 10.1126/science.212.4495.695

950 Falls, J.B. 1985. Song matching in western meadowlarks. Canadian Journal of Zoology 951 63, 2520-2524. doi: 10.1139/z85-373

952 Falls, J.B., Horn, A.G. \& Dickinson, T. E. 1988. How western meadowlarks classify 953 their songs: evidence from song matching. Animal Behaviour 36, 579-585. doi: 954 10.1016/S0003-3472(88)80029-0

955 Falls, J.B., Krebs, J.R. \& McGregor, P.K. 1982. Song matching in the Great Tit (Parus 956 major): the effect of similarity and familiarity. Animal Behaviour 30, 997-1009. doi: $957 \quad 10.1016 / \mathrm{S} 0003-3472(82) 80188-7$

958 Farine, D.R., Spencer, K.A. \& Boogert, N.J. 2015. Early-life stress triggers juvenile 959 zebra finches to switch social learning strategies. Current Biology 25, 2184-2188.

960 Fujimoto, H., Hasegawa, T., \& Watanabe, D. 2011. Neural coding of syntactic structure 961 in learned vocalizations in the songbird. Journal of Neuroscience 31, 10023-10033. doi: 962 10.1523/JNEUROSCI.1606-11.2011

963 Gallup, G.G. 1970. Chimpanzees: self-recognition. Science 167, 86-87. doi: $964 \quad 10.1126 /$ science.167.3914.86

965 Gallup, G.G. \& Capper S.A. 1970. Preference for mirror-image stimulation in finches 966 (Passer domesticus domesticus) and parakeets (Melopsittacus undulatus). Animal 967 Behaviour 18, 621-624. doi:10.1016/0003-3472(70)90004-7

968 George, I., Cousillas, H., Richard, J.-P. \& Hausberger, M. 2005. New insights into the 969 auditory processing of communicative signals in the HVC of awake songbirds. $970 \quad$ Neuroscience 136, 1-14. doi:10.1016/j.neuroscience.2005.08.001 
971 Giret, N., Monbureau, M., Kreutzer, M. \& Bovet, D. 2009. Conspecific discrimination 972 in an object-choice task in African grey parrots (Psittacus erithacus). Behavioural 973 processes $82,75-77$. doi:10.1016/j.beproc.2009.02.016

974 Güntürkün, O., \& Bugnyar, T. 2016. Cognition without Cortex. Trends in cognitive 975 sciences 20, 291-303. doi:10.1016/j.tics.2016.02.001

976 Guyomarc'h, J.-C. 1973. Rôle de l'autoperception auditive dans l'orientation du choix 977 des poussins sans expérience maternelle. Comptes Rendus Academie des Sciences Paris $978 \quad 276,189-192$.

979 Gwinner, E. 1964. Untersuchungen über das Ausdrucks-und Sozialverhalten des 980 Kolkraben (Corvus corax corax L.). Zeitschrift für Tierpsychologie 21, 657-748.

981 Hahnloser, R.H., Kozhevnikov, A.A. \& Fee, M.S. 2002. An ultra-sparse code underlies 982 the generation of neural sequences in a songbird. Nature 419, 65-70. doi: $983 \quad 10.1038 /$ nature00974

984 Hauber, M.E. \& Sherman, P.W. 2001. Self-referent phenotype matching: theoritical 985 considerations and empirical evidence. Trends in Neuroscience 24, 609-616. doi: $986 \quad 10.1016 / \mathrm{S} 0166-2236(00) 01916-0$

987 Hauber, M.E., Sherman, P.W. \& Paprika, D. 2000. Self-referent phenotype matching 988 in a brood parasite: the armpit effect in brown-headed cowbirds (Molothrus ater). Animal 989 Cognition 3, 113-117. doi: 10.1007/s100710000071

990 Henry, L., Le Cars, K., Mathelier, M., Bruderer, C., \& Hausberger, M. 2008. The use 991 of a mirror as a 'social substitute'in laboratory birds. Comptes Rendus Biologies 331, 526992 531. doi:10.1016/j.crvi.2008.04.005 
993 Heyes, C.M. 1994. Reflections on self-recognition in primates. Animal Behaviour 47, 994 909-919. doi: 10.1006/anbe.1994.1123

995 Hill, G.E. 2006. Female mate choice. In: Bird Coloration, Volume 2: Function and 996 Evolution (G. E.Hill \& K. J.McGraw, eds), pp. 137-200. Harvard University Press, 997 Cambridge, MA.

998 Hinde, R.A. 1958. Alternative motor patterns in chaffinch song. Animal Behaviour 6, 999 211-218. doi:10.1016/0003-3472(58)90053-8

1000 Holveck, M. J., \& Riebel, K. 2009. Low-quality females prefer low-quality males when 1001 choosing a mate. Proceedings of the Royal Society of London B: Biological Sciences, 1002 rspb20091222. doi: 10.1098/rspb.2009.1222

1003 Howells, T.H. \& Vine, D.O. 1940. The innate differential in social learning. The 1004 Journal of Abnormal and Social Psychology 35, 537-548. doi: 10.1037/h0063690

1005 Hultsch, H. \& Todt, D. 1982. Temporal performance roles during vocal interactions in 1006 nightingales (Luscinia megarhynchos B.). Behavioural Ecology and Sociobiology 11, 2531007 260. doi: $10.1007 / \mathrm{BF} 00299302$

1008 Itakura, S. 1987. Mirror guided behavior in Japanese monkeys (Macaca fuscata 1009 fuscata). Primates 28, 149-161. doi: 10.1007/BF02382568

1010 Jarvis, E.D., Güntürkün, O., Bruce, L., Csillag, A., Karten, H., Kuenzel, W. \& Butler, 1011 A.B. 2005. Avian brains and a new understanding of vertebrate brain evolution. Nature 1012 Reviews Neuroscience 6, 151-159. doi: 10.1038/nrn1606

1013 Kaufman, I.C. \& Hinde, R.A. 1961. Factors influencing distress calling in chicks, with 1014 special reference to temperature changes and social isolation. Animal Behaviour 9, 1971015 204. doi: 10.1016/0003-3472(61)90009-4 
1016 Kimpo, R.R. \& Doupe, A.J. 1997. FOS is induced by singing in distinct neuronal 1017 populations in a motor network. Neuron 18, 315-325. doi: 10.1016/S0896-6273(00)80271$1018 \quad 8$

1019 King, S.L., \& Janik, V.M. 2013. Bottlenose dolphins can use learned vocal labels to 1020 address each other. Proceedings of the National Academy of Sciences 110, 13216-13221. 1021 doi: 10.1073/pnas.1304459110

1022 Kojima, S. \& Doupe, A.J. 2007. Song selectivity in the pallial-basal ganglia song circuit 1023 of zebra finches raised without tutor song exposure. Journal of Neurophysiology, 98, 20991024 2109. doi: 10.1152/jn.00916.2006

1025 Kondo, N., Izawa, E.I., \& Watanabe, S. 2012. Crows cross-modally recognize group 1026 members but not non-group members. Proceedings of the Royal Society of London B: 1027 Biological Sciences, rspb20112419. doi: 10.1098/rspb.2011.2419.

1028 Krause, E.T. \& Caspers, B.A. 2012. Are olfactory cues involved in nest recognition in 1029 two social species of estrildid finches? PLoS One 7, e36615. 1030 doi:10.1371/journal.pone.0036615

1031 Krause, E.T., Krüger, O., Kohlmeier, P. \& Caspers, B.A. 2012. Olfactory kin 1032 recognition in a songbird. Biology Letters 8, 327-329. doi:10.1098/rsbl.2011.1093

1033 Krebs, J.R., Ashcroft, R., \& Van Orsdol, K. 1981. Song matching in the Great Tit Parus 1034 major L. Animal Behaviour 29, 918-923. doi: 10.1016/S0003-3472(81)80029-2

1035 Kusayama, T., Bischof, H.-J. \& Watanabe, S. 2000. Responses to mirror-image 1036 stimulation in jungle crows (Corvus macrorhynchos). Animal Cognition 3, 61-64. doi: $1037 \quad 10.1007 / \mathrm{s} 100710050051$ 
1039 Quarterly Review of Biology 28, 337-363.

1040 Lemasson, A., Hausberger, M. \& Zuberbühler, K. 2005. Socially meaningful vocal 1041 plasticity in adult Campbell's monkeys (Cercopithecus campbelli). Journal of Comparative 1042 Psychology 119, 220-229. doi:10.1037/0735-7036.119.2.220

1043 Leonardo, A. 2004. Experimental test of the birdsong error-correction model. 1044 Proceedings of the National Academy of Sciences of the United States of America 101, 1045 16935-16940. doi: 10.1073/pnas.0407870101

1046 Lerch, A., Rat-Fischer, L., Gratier, M. \& Nagle, L. 2011. Diet quality affects mate 1047 choice in domestic female canary Serinus canaria. Ethology 117, 769-776. doi: $1048 \quad 10.1111 / \mathrm{j} .1439-0310.2011 .01929 . x$

1049 Lerch, A., Rat-Fischer, L. \& Nagle, L. 2013. Condition-dependent choosiness for 1050 highly attractive songs in female canaries. Ethology 119, 58-65. doi: 10.1111/eth.12037 1051 Lewis, M. 1994. Myself and me. In: self-awareness in animals and humans: 1052 developmental perspectives (ed. S.T. Parker, R.W. Mitchell \& M.L. Boccia), pp. 20-34. 1053 New York: Cambridge University Press.

1054 Lewis, M. 2011. The origins and uses of self-awarenesss or the mental representation 1055 of me. Consciousness and Cognition 20, 120-129. doi.org/10.1016/j.concog.2010.11.002

1056 Lewis, M., \& Ramsay, D. 2004. Development of self-recognition, personal pronoun 1057 use, and pretend play during the 2nd year. Child Development 75, 1821-1831. doi: $1058 \quad 10.1111 / \mathrm{j} .1467-8624.2004 .00819 . \mathrm{x}$

1059 Liberman, A.M. \& Mattingly, I.G. 1985. The motor theory of speech perception 1060 revised. Cognition 21, 1-36. doi:10.1016/0010-0277(85)90021-6 
1061 Manteuffel, C., Schön, P. C., \& Manteuffel, G. 2011. Beyond electronic feeding: The 1062 implementation of call feeding for pregnant sows. Computers and electronics in 1063 agriculture 79, 36-41. doi: 10.1016/j.compag.2011.08.009

1064 Mardon, J. \& Bonadonna, F. 2009. Atypical homing or self-odor avoidance? Blue 1065 petrels (Halobaena caerulea) are attracted to their mate's odor but avoid their own. 1066 Behavioural Ecology and Sociobiology 63, 537-542. doi: 10.1007/s00265-008-0688-z

1067 Margoliash, D. 1983. Acoustic parameters underlying the responses of song-specific 1068 neurons in the white-crowned sparrow. Journal of Neuroscience 3, 1039-1057.

1069 Margoliash, D. 1986. Preference for autogenous song by auditory neurons in a song 1070 system nucleus of the white-crowned sparrow. Journal of Neuroscience 6, 1643-1661.

1071 Margoliash, D. \& Konishi, M. 1985. Auditory representation of autogenous song in the 1072 song system of white-crowned sparrows. Proceedings of the National Academy of Sciences $107382,5997-6000$.

1074 Margoliash, D., \& Schmidt, M.F. 2010. Sleep, off-line processing, and vocal learning. 1075 Brain and language 115, 45-58. doi:10.1016/j.bandl.2009.09.005

1076 Matthews, L.H. 1939. Visual stimulation and ovulation in pigeons. Proceedings of the 1077 Royal Society of London. Series B, Biological Sciences 126, 557-560.

1078 McArthur, P.D. 1986. Similarity of playback songs to self song as a determinant of 1079 response strength in song sparrows (Melospiza melodia). Animal Behaviour 34, 199-207. 1080 doi: 10.1016/0003-3472(86)90024-2

1081 McArthur, P.D. 1987. Auditory self-perception: a reply to Suarez \& Gallup. Animal 1082 Behaviour 35, 612-613. doi: 10.1016/S0003-3472(87)80293-2 
1084 in an avian song control nucleus. Proceedings of the National Academy of Sciences 78, 7815-7819.

1086 McGregor, P.K. 1992. Quantifying responses to playback: one, many, or composite 1087 multivariate measures? In: Playback and studies of animal communication (ed. P.K. Mc 1088 Gregor), pp. 79-96. New York and London: Plenum Press.

1089 McGregor, P.K., \& Krebs, J.R. 1984. Sound degradation as a distance cue in great tit 1090 (Parus major) song. Behavioral Ecology and Sociobiology 16, 49-56. doi: $1091 \quad 10.1007 /$ BF00293103

1092 Medina, F.S., Taylor, A.H., Hunt, G.R. \& Gray, R.D. 2011. New Caledonian crows' 1093 responses to mirrors. Animal Behaviour 82, 981-993. doi: 10.1016/j.anbehav.2011.07.033

1094 Mooney, R. 2000. Different subthreshold mechanisms underlie song selectivity in 1095 identified HVc neurons of the zebra finch. Journal of Neuroscience 20, 5420-5436.

1096 Mooney, R. 2009. Neurobiology of song learning. Current Opinion in Neurobiology 1097 19, 654-660. doi:10.1016/j.conb.2009.10.004

1098 Moravec, M. L., Striedter, G. F., \& Burley, N. T. 2010. 'Virtual parrots' confirm mating 1099 preferences of female budgerigars. Ethology 116, 961-971. doi: 10.1111/j.1439$1100 \quad 0310.2010 .01809 . x$

1101 Morton, E.S. 1982. Grading, discreteness, redundancy, and motivation-structural rules. 1102 In: Acoustic Communication in Birds, Vol I (ed. D. E. Kroodsma \& E.H. Miller), pp. 1831103 211. New York: Academic Press.

1104 Nakamura, K.Z. \& Okanoya, K. 2004. Neural correlates of song complexity in 1105 Bengalese finch high vocal center. Neuroreport 15, 1359-1363. 
1106 Nealen, P. M. \& Schmidt, M. F. 2006. Distributed and selective auditory representation

1107 of song repertoires in the avian song system. Journal of Neurophysiology 96, 3433-3447.

1108 doi: 10.1152/jn.01130.2005

1109 Nick, T.A. \& Konishi, M. 2005a. Neural auditory selectivity develops in parallel with

1110 song. Journal of Neurobiology 62, 469-481. doi: 10.1002/neu.20115

1111 Nick, T.A. \& Konishi, M. 2005b. Neural song preference during vocal learning in the

1112 zebra finch depends on age and state. Journal of Neurobiology 62, 231-242. doi:

$1113 \quad 10.1002 /$ neu.20087

1114 Parker, S.T., Mitchell, R.W., \& Boccia, M.L. 1994. Expanding dimensions of the self:

1115 Through the looking glass and beyond. In: self-awareness in animals and humans:

1116 developmental perspectives (ed. S.T. Parker, R.W. Mitchell \& M.L. Boccia), pp. 3-19. New

1117 York: Cambridge University Press.

1118 Pepperberg, I. M. 1981. Functional vocalizations by an African Grey parrot (Psittacus

1119 erithacus). Zeitschrift für Tierpsychologie 55, 139-160. doi: 10.1111/j.1439-

$1120 \quad$ 0310.1981.tb01265.x

1121 Pepperberg, I.M., Garcia, S.E., Jackson, E.C. \&Marconi, S. 1995. Mirror use by 1122 African Grey Parrots (Psittacus erithacus). Journal of Comparative Psychology 109, 1821123 195. doi: 10.1037/0735-7036.109.2.182

1124 Perez, E. C., Elie, J. E., Soulage, C. O., Soula, H. A., Mathevon, N., \& Vignal, C. 2012. 1125 The acoustic expression of stress in a songbird: Does corticosterone drive isolation-induced 1126 modifications of zebra finch calls? Hormones and Behavior 61, 573-581. doi: 1127 10.1016/j.yhbeh.2012.02.004 
1128 Perez, E.C., Elie, J.E., Boucaud, I.C., Crouchet, T., Soulage, C.O., Soula, H.A.,

1129 Theunissen, F.E. \& Vignal, C. 2015. Physiological resonance between mates through calls

1130 as possible evidence of empathic processes in songbirds. Hormones and Behavior 75, 130-

1131 141. doi: 10.1016/j.yhbeh.2015.09.002.

1132 Péron, F., Rat-Fischer, L., Nagle, L. \& Bovet, D. 2010. 'Unwilling' versus 'unable'. Do

1133 grey parrots understand human intentional actions? Interaction studies 11, 428-441. doi:

$1134 \quad 10.1075 /$ is.11.3.06per

1135 Péron, F., Chardard, C., Nagle, L. \& Bovet, D. 2011. Do African grey parrots (Psittacus

1136 erithacus) know what a human experimenter does and does not see? Behavioural Processes

1137 87, 237-240. doi: 10.1016/j.beproc.2011.04.001

1138 Piaget, J. 1952. The origins of intelligence in children. New York: International 1139 Universities Press.

1140 Pickering, S.P. \& Duverge, L. 1992. The influence of visual stimuli provided by mirrors

1141 on the marching displays of Lesser Flamingos, Phoeniconais minor. Animal Behaviour 43,

1142 1048-1050. doi: 10.1016/S0003-3472(06)80018-7

1143 Platek, S.M., Keenan, J.P., Gallup, G.G. \& Mohamed, F.B. 2004. Where am I? The

1144 neurological correlates of self and other. Cognitive Brain Research 19, 114-122.

1145 doi:10.1016/j.cogbrainres.2003.11.014

1146 Plotnik, J.M., De Waal, F.B., \& Reiss, D. 2006. Self-recognition in an Asian elephant.

1147 Proceedings of the National Academy of Sciences 103, 17053-17057. doi: 1148 10.1073/pnas.0608062103

1149 Povinelli, D.J. 1987. Monkeys, apes, mirrors and minds: the evolution of self1150 awareness in primates. Human Evolution 2, 493-509. doi: 10.1007/BF02437424 
1151 Prather, J.F., Peters, S., Nowicki, S. \& Mooney, R. 2008. Precise auditory-vocal

1152 mirroring in neurons for learned vocal communication. Nature 451, 305-310.

1153 doi:10.1038/nature06492

1154 Prior, H., A. Schwarz, A. \& Güntürkün, O. 2008. Mirror-induced behavior in the

1155 Magpie (Pica pica): evidence of self-recognition. PLoS Biology 6, e202. doi:

1156 10.1371/journal.pbio.0060202

1157 Pytte, C.L. \& Suthers, R.A. 1999. A bird's own song contributes to conspecific song 1158 perception. Neuroreport 10, 1773-1778.

1159 Reiner, A., Perkel, D.J., Mello, C.V., \& Jarvis, E.D. 2004. Songbirds and the revised 1160 avian brain nomenclature. Annals of the New York Academy of Sciences 1016, 77-108. doi: $1161 \quad 10.1196 /$ annals.1298.013

1162 Reiss, D. \& Marino, L. 2001. Mirror self-recognition in the bottlenose dolphin: a case 1163 of cognitive convergence. Proceedings of the National Academy of Sciences USA 98, 5937 1164 5942. doi: 10.1073/pnas.101086398

1165 Remage-Healey, L., Coleman, M.J., Oyama, R.K. and Schlinger, B. 2010. Brain 1166 estrogens rapidly strenghten auditory encoding and guide song preference in a songbird. 1167 Proceedings of the National Academy of Sciences USA 107, 3852-3857. doi: $1168 \quad$ 10.1073/pnas.0906572107

1169 Rochat, P. 2015. Layers of awareness in development. Developmental Review. 1170 doi:10.1016/j.dr.2015.07.009

1171 Roy, A. \& Mooney, R. 2007. Auditory plasticity in a basal ganglia-forebrain pathway 1172 during decrystallization of adult birdsong. Journal of Neuroscience 27, 6374-6387. doi: 1173 10.1523/JNEUROSCI.0894-07.2007 
1174 Ryan, M.J. 1978. Mirror image versus conspecific stimulation in adult male zebra 1175 finches. Wilson Bulletin 90, 295-297.

1176 Salzen, E. A. \& Cornell, J. M. 1968. Self-perception and species recognition in birds.

1177 Behaviour 30, 44-65. doi: 10.1163/156853968X00171

1178 Schneirla, T.C. 1946. Problems in the bio-psychology of social organization. The 1179 Journal of Abnormal and Social Psychology 41, 385-402. doi: 10.1037/h0055210

1180 Searcy, W.A., McArthur, P.D., Peters, S.S. \& Marler, P. 1981. Response of male song 1181 and swamp sparrows to neighbour, stranger, and self songs. Behaviour 77, 152-163. doi: $1182 \quad 10.1163 / 156853981 X 00202$

1183 Searcy, W.A., DuBois, A. L., Rivera-Cáceres, K. \& Nowicki, S. 2013. A test of a 1184 hierarchical signalling model in song sparrows. Animal Behaviour 86, 309-315. 1185 doi:10.1016/j.anbehav.2013.05.019

1186 Sherman, P. W., Reeve, H. K., \& Pfennig, D. W. 1997. Recognition systems. In: 1187 Behavioural ecology: an evolutionary approach, 4th edition (ed. J.R. Krebs \& NB Davies), $1188 \quad 69-96$.

1189 Soler, M., T. Pérez-Contreras, T. \& Peralta-Sánchez, J.M. 2014. Mirror-mark tests 1190 performed on jackdaws reveal potential methodological problems in the use of stickers in 1191 avian mark-test studies. PLoS One 9, e86193. doi: 10.1371/journal.pone.0086193

1192 Solis, M.M. \& Doupe, A.J. 1999. Contributions of tutor and bird's own song experience 1193 to neural selectivity in the songbird anterior forebrain. Journal of Neuroscience 19, 455911944584.

1195 Stirling, I. 1968. Aggressive behavior and the dispersion of female blue grouse. 1196 Canadian Journal of Zoology 46, 405-408. doi: 10.1139/z68-058 
1197 Stoddard, P.K., Beecher, M.D., Campbell, S.E., \& Horning, C.L. 1992. Song-type 1198 matching in the song sparrow. Canadian Journal of Zoology 707, 1440-1444. doi: $1199 \quad 10.1139 / \mathrm{z} 92-200$

1200 Stout, J.F., \& Wilcox C.R. \& Creitz, L.E. 1969. Aggressive communication by Larus 1201 Glaucescens Part I. Sound Communication. Behaviour 34, 29-41. doi: $1202 \quad 10.1163 / 156853969 X 00396$

1203 Suarez, S.D. \& Gallup, G.G. 1986. Social responding to mirrors in rhesus macaques 1204 (Macaca mulatta): Effects of changing mirror location. American Journal of Primatology 1205 11, 239-244. doi: 10.1002/ajp.1350110305

1206 Suarez, S.D. \& Gallup, G.G. 1987. The question of an auditory self-concept in song 1207 sparrows, Melospiza melodia. Animal behaviour 35, 610-612. doi: 10.1016/S0003$1208 \quad 3472(87) 80293-2$

1209 Suddendorf, T., \& Butler, D. L. 2013. The nature of visual self-recognition. Trends in 1210 Cognitive Sciences 17, 121-127. doi:10.1016/j.tics.2013.01.004

1211 Takahashi, D. Y., Fenley, A. R., Teramoto, Y., Narayanan, D. Z., Borjon, J. I., Holmes, 1212 P. \& Ghazanfar, A. A. 2015. The developmental dynamics of marmoset monkey vocal 1213 production. Science 349, 734-738. doi: 10.1126/science.aab1058

1214 Ter Maat, A., Trost, L., Sagunsky, H., Seltmann, S., \& Gahr, M. 2014. Zebra finch 1215 mates use their forebrain song system in unlearned call communication. PLoS One, 1216 e109334. doi: 10.1371/journal.pone.0109334

1217 Thompson, R.K.R., Contie, C.L., 1994. Further reflections on mirror-usage by pigeons: 1218 lessons from Winnie-the-Pooh and Pinocchio too. In: self-awareness in animals and 
1219 humans: developmental perspectives (ed. S.T. Parker, R.W. Mitchell \& M.L. Boccia), pp. 1220 392-410. New York: Cambridge University Press.

1221 Toda, K. \& Watanabe, S. 2008. Discrimination of moving video images of self by 1222 pigeons (Columba livia). Animal cognition 11, 699-705. doi: 10.1007/s10071-008-0161-4 1223 Todt, D. 1970. Gesangliche Reaktionen der Amsel (Turdus merula L.) auf ihren 1224 experimentell reproduzierten Eigengesang. Zeitschrift für vergleichende Physiologie 66, 1225 294-317. doi: 10.1007/BF00297831

1226 Todt, D. 1975. Short term inhibition of outputs occurring in the vocal behaviour of 1227 blackbirds (Turdus merula m. L.). Journal of Comparative Physiology 98, 289-306. doi: $1228 \quad 10.1007 / \mathrm{BF} 00709802$

1229 Todt, D. 1981. On Functions of Vocal Matching: Effect of Counter-replies on Song 1230 Post Choice and Singing. Zeitschrift für Tierpsychologie 57, 73-93. doi: 10.1111/j.1439$1231 \quad$ 0310.1981.tb01313.x

1232 Uchino, E. \& Watanabe, S. 2014. Self-recognition in pigeons revisited. Journal of the 1233 experimental analysis of behavior 102, 327-334. doi: 10.1002/jeab.112

1234 Van der Kant, A., Derégnaucourt, S., Gahr, M., Van der Linden, A. \& Poirier, C. 2013. 1235 Representation of early sensory experience in the adult auditory midbrain: Implications for 1236 vocal learning. PLoS One, e61764. doi: 10.1371/journal.pone.0061764

1237 Van Horik, J. \& Emery, N. J. 2011. Evolution of cognition. Wiley Interdisciplinary 1238 Reviews: Cognitive Science 2, 621-633. doi: 10.1002/wcs.144

1239 Vidal, J.-M. 1975. Influence de la privation sociale et de "l'autoperception" sur le 1240 comportement sexuel du coq domestique. Behaviour 52: 57-83. doi: $1241 \quad 10.1163 / 156853975 X 00119$ 
1242 Volman, S.F. 1993. Development of neural selectivity for birdsong during vocal 1243 learning. Journal of Neuroscience 13, 4737-4747.

1244 Wanker, R., Sugama, Y. \& Prinage, S. 2005. Vocal labelling of family members in 1245 spectacled parrotlets, Forpus conspicillatus. Animal Behaviour 70, 111-118. doi: $1246 \quad 10.1016 /$ j.anbehav.2004.09.022

1247 Watanabe, S. 2002. Preference for mirror images and video image in Java sparrows 1248 (Padda oryzivora). Behavioural Processes 60, 35-39. doi: 10.1016/S0376-6357(02)0009412493

1250 Weary, D.M., Falls, J.B. \& McGregor, P.K. 1990. Song matching and the perception 1251 of song types in Great Tits, Parus major. Behavioral Ecology 1, 43-47.

1252 Weeden, J. S. \& Falls, J.B. 1959. Differential responses of male ovenbirds to recorded 1253 songs of neighboring and more distant individuals. Auk 76, 323-351.

1254 Williams, H. \& Nottebohm, F. 1985. Auditory responses in avian vocal motor neurons: 1255 a motor theory for song perception in birds. Science 229, 279-282. doi: $1256 \quad 10.1126 /$ science.4012321

1257 Wolffgramm, J., \& Todt, D. 1982. Pattern and time specificity in vocal responses of 1258 blackbirds Turdus merula L. Behaviour 81, 264-285. doi: 10.1163/156853982X00166 1259 Yasukawa, K., Bick, E.I., Wagman, D.W., \& Marler, P. 1982. Playback and speaker1260 replacement experiments on song-based neighbor, stranger, and self-discrimination in male 1261 red-winged blackbirds. Behavioral Ecology and Sociobiology 10, 211-215. doi: $1262 \quad 10.1007 / B F 00299687$ 
1263 Yuval-Greenberg, S. \& Deouell, L.Y. 2009. The dog's meow: asymmetrical interaction 1264 in cross-modal object recognition. Experimental Brain Research 193, 603-614. 1265 doi:10.1007/s00221-008-1664-6

1266 
1269 Table 1. List of species that were tested with the Mirror Self Recognition Paradigm.

1270 We did not include primates in this table because the literature relative to them is very

1271 abundant and the present paper focuses on birds. The current consensus concerning

1272 primates is that great apes pass the mark test, whereas monkeys do not pass that test,

1273 although they may do it after extensive training (for reviews, see for example Anderson \&

1274 Gallup, 2011, 2015; Suddendorf and Butler, 2013).

1275 
1278 Figure 1. Avian and mammalian brains contain homologous structures and similar

1279 functional circuitry.(a) Midline sagittal section of a human brain showing major 1280 structures, including those involved in generating conscious states (e.g. cortex, thalamus, 1281 and basal ganglia).(b) Midline sagittal section of the brain of a zebra finch, a songbird. 1282 Major neural structures are shown, including those with mammalian homologs. Also 1283 shown is a greatly simplified schematic of the anterior forebrain pathway for song learning 1284 (yellow arrows) involving components of the basal ganglia, including the striatal nucleus 1285 Area $X$ (' $X$ ' in filled red circle). The circular inset to right of human brain shows zebra 1286 finch brain to scale for comparison. Adapted from Edelman \& Seth, Trends in 1287 Neurosciences 2009.

1289 Figure 2. Relative brain size across birds and mammals. Graphs displaying the 1290 relationship between (log) body weight and (log) brain volume acroos various birds and 1291 mammals (e.g. corvids, parrots, apes, dolphins, Australopithecus and modern Homo 1292 sapiens, pigeons and rats. Adapted from Van Horik \& Emery, Wiley Interdisciplinary 1293 Reviews: Cognitive Science 2011.

1295 Figure 3. Adapted version of the mark test developed by Gordon Gallup with magpies 1296 (Pica pica). (A) Attempt to reach the mark with the beak; (B) touching the mark area with 1297 the foot; (C) touching the breast region outside the marked area; (D) touching other parts 1298 of the body. Behaviours (A) and (B) entered the analysis as mark-directed behaviour; 
1299 behaviours (C) and (D) and similar actions towards other parts of the body were considered 1300 self-directed, but not related to the mark. Adapted from Prior et al., PLoS Biology 2008.

1302 Figure 4. Schematic representation of the avian song control system and its auditory

1303 inputs. The avian song system can be divided into three main divisions. The descending 1304 motor pathway (shown in black) includes telencephalic areas HVC and RA as well as 1305 brainstem nuclei that drive the muscles of the syrinx (nXIIts) or the respiratory system 1306 (Ram and PAm). These later two structures form part of a vocal respiratory network that 1307 also includes DM. The second division, sometimes called the ventral motor pathway, 1308 consists of projections from the diencephalon and brainstem back to HVC (shown in 1309 green). The third major division of the song system consists of the anterior pathway (shown 1310 in light red), which is made up of Area X, DLM, and LMAN. The song system receives 1311 processed auditory information from an ascending auditory pathway (shown in blue).

1312 Areas where BOS-selective responses have been recorded are outlined in red. Anatomical 1313 names: DLM, medial part of the dorsolateral thalamic nucleus; LMAN, lateral 1314 magnocellular nucleus of the anterior nidopallium; Field L is the primary auditory 1315 forebrain structure in birds; Area $X$, Area $X$ of the medial striatum; NIf, nucleus 1316 interfacialis of the nidopallium; RAm, nucleus retroambigualis; PAm, nucleus 1317 paraambigualus; DM, dorsomedial nucleus of the intercollicular complex; CMM, caudal 1318 medial mesopallium; CLM, caudal lateral mesopallium; Field L, auditory forebrain areas 1319 consisting of Field L1, L2, L2a, L2b and L3; Ov/Ovm, nucleus ovoidalis; MLd, dorsal 1320 lateral nucleus of the mesencephalon; NCM, caudal medial nidopallium; LLV, ventral 
1321 nucleus of the lateral lemniscus; EXP, expiration; INSP, inspiration. Adapted from 1322 Margoliash \& Schmidt, Brain \& Language 2010.

1324 Figure 5. Vocal labelling in spectacled parrotlets (Forpus conspicillatus). Spectrograms

1325 of contact calls from the male Eddi interacting with different partners. (a, d, g) Eddi 1326 interacting with his pair mate Renee, (b, e, h) Eddi interacting with his offspring Ustinov 1327 and (c, f, i) Eddi interacting with his offspring Uvo. (Fast Fourier Transformation (FFT) 1328 window size: 256 pts; frequency resolution: $125 \mathrm{~Hz}$; time resolution: $8.0 \mathrm{~ms}$; number of 1329 FFTs: 500 steps). Adapted from Wanker et al., Animal Behaviour 2005. 